\title{
Characteristic of Erosion Properties and Relationship With Geotechnical Properties for Red Riverbank Soil in Hanoi, Vietnam
}

Toan Thi Duong ( $\boldsymbol{\sim}$ duongtoan@hus.edu.vn )

Vietnam National University University of Science

\section{Research Article}

Keywords: Critical shear stress, Soil erosion rate, Grain size, Dry density, Shear strength, Residual suction.

Posted Date: April 19th, 2021

DOl: https://doi.org/10.21203/rs.3.rs-385677/v1

License: (c) (i) This work is licensed under a Creative Commons Attribution 4.0 International License.

Read Full License 


\section{Characteristic of erosion properties and relationship with geotechnical properties for Red riverbank soil in Hanoi, Vietnam}

\section{Introduction}

Riverbank erosion is one main mechanics of lateral river migration leading to riverbank hazards and losing land. Two main processes relating to riverbank soil erosion are the river flow dynamic and surface erosion by heavy rainfall (Abidin et al. 2017). In this paper, the first process as undercutting erosion of riverbank by water flow shear stress will be concerned. The erosion properties are important factors in the analysis of riverbank cantilever failure (Darby et al. 2007; Simon et al. 2011; Yong et al. 2014; Patsinghasanee 2018; Toan and Duc 2019), and riverbank failure risk (Abidin et al. 2017). They include the critical shear stress, the initial erosion slope, the erosion curve slope, the erosion rate (Shafii et al. 2016). The critical shear stress as the threshold of soil erosion is the flow shear stress at which soil starts erosion. The soil erosion rate is defined as the soil column high ( $\mathrm{mm}$ ) eroded per unit time (hour) in the erosion flume testing. Soil eroding happen when the applied shear stress is higher than the critical shear stress (Briaud 2008). The critical shear stress may difficult to directly measure during the erosion test, which can be determined by the erosion curve (the graph of shear stress versus the soil erosion rate). In the erosion curve, the critical shear stress is value responding to the erosion rate of $0.1 \mathrm{~mm} /$ hour and at which the line of the first two points of the erosion curve crosses with the horizontal axis (Shafii et al. 2016). The measurement technique for determining the soil erosion properties can be carried out in laboratories using a channel flume set up lateral (Bo et al. 2011; Yu et al. 2015; Patsinghasanee et al 2018) or on the bottom of a water flow channel (Briaud 2008; Berlamont et al. 1993; Badr et al. 2002) with the abundant size of length and width as the shape of the flume. A few research used simple soil columns (Benamar et al. 2012), submerged impinging jets (Regazzoni and Marot 2011; Montoya 2018; Benseghier 2020) and calculated the soil erosion properties from the previous experiment equations.

Many factors that affect soil erosion properties were overviewed and generally divided into three groups of influence factors (Grabowski, 2011): (1) geotechnical engineering properties such as the average particle size, particle size distribution, bulk density, and water content; (2) geochemical properties such as clay mineralogy, water geochemistry (dissolved ions, $\mathrm{pH}$, metals), and organic contents; and (3) biological properties such as feeding and egestion and biogenic structures (burrows, network-roots, integrated biofilm, and extracellular polymeric substances). Some research focused on analyzing the effects of structure and surface roughness of sand-clay mixture (Das 2019; Barman 2019), the characteristic of riverbank 
morphograph, flow hydrodynamic (Li, 2020; Roy 2020), and vegetable covering on the riverbank. The soil geotechnical properties as the effects of the grain size distribution, soil bulk density, and shear strength will be determined and discussed here in the relationships with the erosion properties.

The most meticulous and successful results of the relation between soil properties and the erosion rate were found in a series of studies and papers published by Briaud and his colleagues (Shafii et al. 2016; Briaud 2008; Briaud et al 1999, 2001a, 2001b). Based on 15 years of erosion testing experience using erosion function apparatus (EFA), a series erosion categories depending on the classification of soils or rocks was proposed (Briaud 2008). For practical use, these erosion categories are used to select tested and protected material. However, the structure and density of mixture soil were not mention in these erosion categories. The grain size effects were also analysed in the variation of mud or fines content (silt and clay) in the mixture (Mitchener and Torfs 1996; Couper 2003; Ahmad et al. 2011; Jacobs et al. 2011; Benamar et al. 2012), in cohesive soils (Berlamont et al.1993; Jianfar 2014). In mixed soils, the clay content or silt content variation, defined as the weight of both silt and clay contents, is added to sand or vice versa. Results reported from earlier studies have demonstrated that adding fine content (mud/silt, clay) more drastically changes critical soil erosion than when adding sand to mud sediment (Mitchener and Torfs 1996; Panagiotopoulos et al. 1997; Van Ledden 2004). The addition of small percentages of mud by weight to sand leads the strongest effect on erosion resistance (Mitchener and Torfs 1996). The mode of erosion also changes from cohesion-less to cohesive behavior for low fine contents added to sand, with a transition occurring in the region of $3 \%$ to $15 \%$ mud by weight. Two sand-mud mixtures were conducted in (Panagiotopoulos et al. 1997): one regime for mud contents less than $30 \%$ (clay mineral content $10 \%$ ) and another for contents greater than $30 \%$. These two unimodal sands were mixed separately with various proportions of Combwich mud by dry weight of $5 \%, 10 \%, 20 \%, 30 \%, 40 \%$, and $50 \%$, which respectively correspond to $1.8,3.6,7.2$, $10.8,14.4$, and $18 \%$ of clay mineral. The experimentally obtained results depend on the flow conditions and clay contents. Results concluded that the linear increase occurs only in steady conditions. Under oscillatory flow conditions, the threshold criterion used was not significant when the clay content was $\leq 11 \%$. Otherwise, the mean critical shear stress increases dramatically when the clay content approaches $50 \%$. Also assess the effect grain size content on the erosion properties, but there is no correlation between the critical shear stress and erosion slope found in (Kimiaghalamn et al. 2016)

The effects of bulk density on erosion rates and critical shear stress of uniform size quartz particles from fine-grained (5 $\square \mathrm{m}$ diameter) to coarse grained (1,350 $\square \mathrm{m}$ diameter) sediments were assessed in (Jepsen 
et al. 1997; Roberts et al. 1998; Lick and McNeil 2001). The erosion rate was demonstrated as a unique function of bulk density and that it decreases as the bulk density decreases for compacted soil samples (Jepsen 1997). The critical shear stresses of finer particles were strongly dependent on the particle size and bulk density in fine soil. However, that were strongly dependent only on the particle size in larger particle soil (Jepsen et al. 1997; Roberts et al. 1998; Lick and McNeil 2001). The linear relation between the density and degree of compaction in the soil column with the soil erosion rate was also demonstrated in (Lick and McNeil 2001).

The relationship between soil erosion and other soil properties such as shear strength was also built in recent research (Kimiaghalam et al. 2016; Léonard and Richard 2004; Fattet et al. 2011; Boudreaux 2012). The shear strength was used as a key factor characteristic of the resistance properties to erosion in the mixture soil with vegetation in (Fattet et al. 2011; Boudreaux 2012). That research found that a significant positive linear relationship between mean weight diameter and soil cohesion but not with the internal angle of friction. Some empirical equations to determine the critical shear stress by the function of the shear strength and other properties were built and overviewed in (Kimiaghalam et al. 2016). That research also assessed some properties to the soil erosion but found the strongest correlation between the critical shear stress and cohesion force. The increase in cohesion force causes an increase in the critical shear stress. The correlation of the only total shear stress and the critical shear stress, and a function of two factors were built with a high coefficient of determination $\left(R^{2}=0.93\right)$ in (Léonard and Richard 2004). That research also found that the relationship does not depend on soil texture, and found obviously in undisturbed soil rather than remound soil.

Although soil erosion is an important factor in the analysis of riverbank undercutting erosion, the determining process of soil erosion is still difficult. Moreover, the limitation in analyses of riverbank cantilever failure was at the quantification of the fluvial erosion rate because the determination of erosion coefficient remains complex, and varies from one site to another. There were varietal conclusions on the effects of soil geotechnical properties on the mixture soil. The critical shear stress and erosion curve need measuring locally (Patsinghasanee et al. 2017; Goharrokhi 2015). Moreover, those results mostly emphasized only the critical erosion shear stress, the soil erosion rate characteristics and the processing of soil erosion were limited. Analyzing riverbank stability requires not only the critical shear stress but also the soil erosion curve. Determined the soil erosion rate curve is required in the analysis of riverbank stability in the type of cantilever failure. 
This paper presents attempts to ascertain the characteristics of soil erosion properties using modified water flume model testing equipment in the laboratory. Determining the critical shear stress and erosion rate curve not only for finding the local soil erosion characteristic but also for assessing their effects on riverbank stability in further researches and analysis. Results of the present research conducted for analyses of riverbank and river channel stability suggest that when a river dyke is subjected to strong hydraulic flow such as river flow or run-off caused by heavy rainfall, soil erosion is likely to occur at the riverbank toe or near the riverbank zone, endangering them and leading to overhang-shaped damage. Eventually, the riverbank will fail. For clarification of this mechanism, however, analyses of riverbank stability with the accounting of soil erosion are required. Therefore, the authors must find a more accurate model that can accommodate precise numerical simulation.

The relationship between the soil erosion properties and the soil grain size, density, shear strength, and residual suction will be built and discussed. While the residual suction is soil suction when the riverbank changes from unsaturated to saturated by river water level increase. That value is presented in Figure 1, the suction at the end of the wetting process. By submerged under river water level and high flow shear stress, the soil may already erosion. However, in some clay soil with high cohesion, some air still exists in soil aggregate and the residual suction still exists. Moreover, this value indicates soil resistance properties under the attack of loading and shear stress. The relationship between residual suction and erosion properties gives engineers more options for properties for riverbank protection.

\section{Materials and Methods}

\subsection{Soil materials}

Field investigations were carried out along the riverbank of the Red River, which flows through Hanoi, Vietnam's national capital. The detailed investigated sites are the natural riverbank and have high erosion potential. Soil samples were gathered at these locations as presented in Figure 2.

Soil materials collected along the surface of the banks of the Red River include both undisturbed and disturbed soil samples. Water contents and bulk density were measured directly in the field using a steel container and steel ring according to the ASTM standard (ASTM D 2216 and ASTM D 2937-00, respectively). Soil samples were used to assess the soil grain size, erosion, suction, shear strength, and hydraulic conductivity for simulation in the laboratory according to natural water contents, bulk density, and the predetermined dry density. The detail for these geotechnical properties were descripted in previous project (Toan 2014). This paper specifically examines description of the characteristics of soil erosion 
properties and build the relationships with these geotechnical properties. Soils of nine types, which are representative soils for samples from the banks of the Red River, can be arranged into three groups: the Clay group, Silt I group, and Silt II group (Table 1).

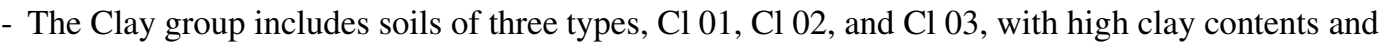
the low sand contents with less than $2 \%$ in this group. Sample $\mathrm{Cl} 03$ has the lowest clay content of 36.0\%; $\mathrm{Cl} 02$ and $\mathrm{Cl} 01$ have respective clay contents of $42.4 \%$ and $70.0 \%$. 
Table 1 Physical soil properties and soil classification of samples collected from the Red River bank (Toan 2014)

\begin{tabular}{|c|c|c|c|c|c|c|c|c|c|c|}
\hline \multirow{2}{*}{\multicolumn{2}{|c|}{ Description }} & \multicolumn{3}{|c|}{ Clay $(\mathrm{Cl})$} & \multicolumn{3}{|c|}{ Silt I (Silt-Clay) } & \multicolumn{3}{|c|}{ Silt I (Silt-Sand) } \\
\hline & & $\mathrm{Cl} 01$ & $\mathrm{Cl} 02$ & $\mathrm{Cl} 03$ & SiltI-01 & Silt I-02 & Silt I-03 & Silt II-01 & Silt II-02 & Silt II-03 \\
\hline \multicolumn{2}{|c|}{ Name of field sample } & NT22 & NT21 & NT 01 & NT 03 & PT06 & HB21 & HB 01 & NT 04 & $\mathrm{XC}$ \\
\hline \multirow{2}{*}{$\begin{array}{l}\text { Sand } \\
(\%)\end{array}$} & $1-0.25 \mathrm{~mm}$ & 0 & 0 & 0 & 0 & 0 & 0 & 0 & 0 & 0 \\
\hline & $0.25-0.075 \mathrm{~mm}$ & 1.4 & 1.2 & 1.3 & 4.0 & 9.8 & 14.5 & 20.3 & 25.5 & 36.6 \\
\hline $\begin{array}{l}\text { Silt } \\
(\%)\end{array}$ & $0.075-0.005 \mathrm{~mm}$ & 28.6 & 56.4 & 62.7 & 70.0 & 70.8 & 70.0 & 69.7 & 64.5 & 53.4 \\
\hline $\begin{array}{l}\text { Clay } \\
(\%)\end{array}$ & $<0.005 \mathrm{~mm}$ & 70.0 & 42.4 & 36.0 & 25.0 & 19.4 & 15.5 & 10.0 & 10.0 & 10.0 \\
\hline \multicolumn{2}{|c|}{ Natural water content $(\%)$} & 32.68 & 32.42 & 28.44 & 28.20 & 37.25 & 30.52 & 19.42 & 11.12 & 16.06 \\
\hline \multicolumn{2}{|c|}{ Bulk density $\left(\mathrm{kN} / \mathrm{m}^{3}\right)$} & 19.5 & 19.9 & 19.6 & 18.7 & 19.0 & 18.0 & 18.5 & 16.8 & 17.3 \\
\hline \multicolumn{2}{|c|}{ Dry density $\left(\mathrm{kN} / \mathrm{m}^{3}\right)$} & 14.7 & 15.0 & 15.3 & 15.7 & 13.8 & 13.8 & 14.4 & 15.1 & 14.9 \\
\hline \multicolumn{2}{|c|}{ Max dry density $\left(\mathrm{kN} / \mathrm{m}^{3}\right)$} & & & & 17.4 & & 17.4 & 1.67 & & 17.9 \\
\hline \multicolumn{2}{|c|}{ Optimal water content (\%) } & & & & 14.2 & & 14.5 & 16.2 & & 15.5 \\
\hline \multicolumn{2}{|c|}{ Specific gravity } & 2.75 & 2.72 & 2.57 & 2.61 & 2.63 & 2.62 & 26.4 & 2.64 & 2.62 \\
\hline \multicolumn{2}{|c|}{ Liquid limit (\%) } & 57.98 & 57.01 & 42.45 & 34.36 & 38.67 & 37.77 & 34.36 & - & 27.92 \\
\hline \multicolumn{2}{|c|}{ Plastic limit (\%) } & 31.35 & 24.14 & 17.5 & 24.06 & 31.23 & 25.63 & 23.06 & - & 19.35 \\
\hline \multicolumn{2}{|c|}{ Plasticity index } & 26.63 & 32.87 & 24.94 & 10.3 & 7.44 & 12.14 & 11.30 & - & 8.57 \\
\hline \multicolumn{2}{|c|}{ Soil classification } & MH & $\mathrm{CH}$ & $\mathrm{CL}$ & ML & ML & ML & $\mathrm{CL}$ & & $\mathrm{CL}$ \\
\hline
\end{tabular}

The silt soils were classified into two groups: Silt I and Silt II.

- Silt I has silt grain content of about $70 \%$, with clay contents decreasing from $25.0 \%$ for Silt I-01 to $19.4 \%$ for Silt I-02, and to $15 \%$ to Silt I-03 corresponding to an increase of sand contents.

- Silt II group has the same clay content at $10 \%$, with sand content increasing by $20.3 \%, 25.5 \%$, and 36.6\%, respectively, for Silt II-01, Silt II-02, and Silt II-03. Table 1 and Figure 3 show the physical soil properties and grain size distribution curves of samples collected along the banks of the Red River in Hanoi, Vietnam.

\subsection{Soil erosion test method}

Soil bank erosion by water flow stress was simulated and interpolated based on soil movement. The concept of determining soil erosion in an open pipe is simulated using the erosion function apparatus invented (Briaud et al 1999, 2001a, 2001b; Briaud 2008). The equipment includes an open rectangular pipe with 2 $\mathrm{m}$ length, $0.2 \mathrm{~m}$ width, and $0.1 \mathrm{~m}$ height. Figure 5, 6, 7 show the configuration and photographs of the soil test apparatus. Water flowing in the pipe is supplied from a water tank. Opening a water valve at the bottom 
of the water tank controls the water velocity, which is measured during the test. The water pipe slope and the water tank height can also be changed to control the water velocity. A cylindrical mould with the diameter $7.6 \mathrm{~cm}$ is attached to the bottom of the test pipe is used to compact the soil sample. The protrusion of soil in this mould can be manipulated using hand controls (Figure 6). During the test, the time necessary to erode at a certain soil height by water flow in a simulated opening channel is measured. The ratio of the eroded height $(\mathrm{mm})$ to the elapsed time $(\mathrm{hr})$ is defined as the soil erosion rate $(\mathrm{mm} / \mathrm{hr})$.

The soil sample was mounted into the sample cylinder with predetermined water contents and dry density. Before the test, the core soil is made to protrude at intervals of $1 \mathrm{~mm}$ (Figure 7). The open the water valve at a predetermined velocity $(\mathrm{m} / \mathrm{s})$. To ascertain the critical shear stress, the first test water velocity is set sufficiently small that one can see that soil is starting to erode. Record the time it takes to erode $1 \mathrm{~mm}$ or $\square \mathrm{h}(\mathrm{mm})$ soil core. This is the duration of time $\square t(\mathrm{hr})$ it takes to erode the soil of height $\square h(\mathrm{~mm})$. The test results are given as the relation between the soil erosion rate and the water velocity or shear stress (Figure 8).

\subsection{Determining erosional rate and shear stress}

The results of this analysis represent the relationship between erosion rate and shear stress, in which the erosion rate and shear stress are calculated using the following equations. The soil erosion rate ( $\square$ ) is the ratio of the height of the eroded soil ( $\square h$ ) to the elapsed time ( $\square t$ ) (Briaud et al 1999, 2001a, 2001b; Briaud 2008; Julien 2002; Mobley 2009).

$\square=\square h / \square t$

The shear stress from the water flow can be calculated using the Moody chart

$\tau=\frac{\rho f V^{2}}{8}$

in which $(\square)$ is the shear stress $\left(\mathrm{N} / \mathrm{m}^{2}\right.$ or Pa), $(\rho)$ is the density of water, $(V)$ is the average water velocity, and $(f)$ is a friction coefficient. Theoretically, $(f)$ is obtained from the Moody diagram using the relative roughness (roughness height/conduit diameter) and the Reynolds number $\left(R_{e}\right)$, which is calculated as:

For $R_{e}>3000$ : 
when $\operatorname{Re}<105$, the equation above can be approximated as presented below.

$$
f=\frac{0.316}{R_{e}^{1 / 4}}
$$

Where the Reynolds number (Re) is determined by Eq. 5:

$$
R_{e}=\frac{V D}{v}
$$

$(D)$ is the hydraulic diameter of the pipe and $(v)$ is the kinematic viscosity of water. The hydraulic diameter is calculated as:

$$
D=\frac{2 a b}{(a+b)}
$$

The open pipe is assumed to be smooth; (a) represents the width, and $(b)$ represents the height of water flow in the open pipe. For turbulent flow in smooth conduits, the following approximations of the friction coefficient and the Reynolds number dependence can be used.

Finally, the results are presented by the erosion curve as shown in Figure 8, is relationship between the soil erosion rate and the water flow shear stress. In the curve relating soil erosion rates and water stress, the critical shear stress $\left(\tau_{c}\right)$ is defined as the stress value at which soil begins to erode, at which the soil erosion rate as $0.1 \mathrm{~mm} /$ hour (Shafii et al. 2016).

\section{Results and discussion}

In this paper, nine types of soil with difference of grain size content was selected and all these soils were tested at the dry density of $15.0 \mathrm{kN} / \mathrm{m}^{3}$. Only four soils as Silt II-03, Silt I-03, Silt I-01, and Cl-03 were carried out at more density of 13.5 and $16.5 \mathrm{kN} / \mathrm{m}^{3}$.

Results of tests conducted to ascertain the soil erosion behavior under typical water velocities and the water shear stresses for soils at the dry density of $15.0 \mathrm{kN} / \mathrm{m}^{3}$ are presented in Figure 9. In the low flow velocity 
and shear stress (less than $0.2 \mathrm{~m} / \mathrm{s}$ and $5 \mathrm{~Pa}$ ), it is difficult to see clarify the deference erosion rate at deference soil. However, almost the silty soil (group Silt I and Silt II) were eroded. In this stage, there is a important factor required to determine as the critical shear stress, which the soil was start eroded. By recording during the erosion testing and drawing the initial stage of the relationship of the flow shear stress and erosion rate the critical shear stress were pointed out.

The critical shear stresses for Silt I and Silt II groups are small, they are nearly equal among all soils of these groups, 0.7-1.5 Pa. Especially, the critical shear stress is the same, about $1 \mathrm{~Pa}$ in group Silt II. Critical shear stresses for the Clay group are higher and are quite different for each soil, at 5.55-7.81 Pa.

Besides the critical shear stress, other properties of soil erosion will be extracted. These include the initial slope $\left(K_{i}\right)$ which is the slope of the erosion curve at the initial stage with the water flow shear stress less than $5 \mathrm{~Pa}$, and the erosion slope $(K)$ which is the slope of the erosion curve with the flow shear stress higher than $5 \mathrm{~Pa}$, see in Table 2.

The initial slope of soil is lower than the erosion slope in almost all soils. That means the erosion rate increase slowly when the shear stress is low, then increases quickly when shear stresses higher than $5 \mathrm{~Pa}$. The relationship of these properties with the soil grain size content (sand/silt/clay content, the mean grain size diameter $D_{50}$, the grain size slope); soil density, shear strength (cohesion force and internal friction angle), and the residual suction. Table 2 and Figure 10 to Figure 21 present the erosion properties and some geotechnical properties, and these relationship graphs, the characteristics of these relationships will be discussed following.

Table 2 The soil erosion properties and geotechnical engineering properties

\begin{tabular}{lccccccccc}
\hline \multicolumn{1}{c}{ Soil types } & $\begin{array}{c}\square_{c} \\
(\mathrm{~Pa})\end{array}$ & $K_{i}$ & $K$ & $\begin{array}{c}D_{50} \\
(\mathrm{~mm})\end{array}$ & $\begin{array}{c}\text { Grain } \\
\text { size } \\
\text { slope }\end{array}$ & $\begin{array}{c}\text { Effective } \\
\text { cohesion } \\
(\mathrm{c}, \mathrm{kPa})\end{array}$ & $\begin{array}{c}\text { Internal } \\
\text { friction } \\
\text { angle } \\
(\text { degree })\end{array}$ & $\begin{array}{c}\text { The } \\
\text { residual } \\
\text { suction } \\
(\mathrm{kPa})\end{array}$ \\
\hline Cl 01 & NT22 & 7.10 & 1.02 & 1.02 & 0.0016 & 3.94 & 50 & 30 & 61.0 \\
Cl 02 & NT21 & 6.50 & 1.52 & 1.52 & 0.0056 & 7.69 & & & 57.8 \\
Cl 03 & NT01 & 4.00 & 1.52 & 4.35 & 0.0090 & 9.09 & 32 & 29 & 53.1 \\
Silt I-01 & NT03 & 1.50 & 3.87 & 4.76 & 0.0130 & 10.15 & 15 & 32.1 & 35.8 \\
Silt I-02 & PT06 & 1.50 & 9.97 & 10.88 & 0.0170 & 10.11 & 12 & 32.4 & 29.5 \\
Silt I-03 & HB21 & 1.00 & 11.20 & 25.32 & 0.0195 & 10.15 & 10 & 32.1 & 28.4 \\
Silt II-01 & HB01 & 1.20 & 7.27 & 29.50 & 0.0160 & 9.95 & 10 & 32.1 & 30.1 \\
Silt II-02 & NT04 & 1.00 & 23.09 & 36.42 & 0.0220 & 9.21 & 10 & 32.4 & 28.1 \\
Silt II-03 & XC & 0.70 & 28.79 & 26.96 & 0.0400 & 7.63 & 7 & 30.9 & 16.6 \\
\hline
\end{tabular}




\subsection{The effects of grain size on erosion properties}

The effects of grain size on the soil erosion properties are assessed based on the relationship of the soil grain size content (sand, silt, and clay content), of the mean grain size $D_{50}$, and of the grain size curve slope on the critical shear stress and on the erosion slope as shown in Figure 10 to Figure 15, respectively. The results of the coefficient of determination $\left(R^{2}\right)$ in Figure 10 shows that the critical shear stress has a strong correlation with the clay content with $R^{2}=0.91$, but a quite weak correlation with the sand and silt content $\left(R^{2}=0.57\right.$ and 0.49 for with silt and sand content, respectively). Contrary to the critical shear stress, the correlation of the initial erosion and erosion slope with sand content is stronger with sand content than clay and silt content. Figure 11 shows only the relationship between the slope of erosion curve and sand content, with the $R^{2}=0.89$ and 0.76 , while that value with clay and silt content are not shown here but very small. That means the soil with high sand content, the slope of erosion curve at both the initial stage and highshear stress, and the erosion rate obtained higher.

Figure 12 and 14 indicate the relationships of the critical shear stress with mean grain size $\left(D_{50}\right)$ and the grain size curve slope. Figure 13 and 15 are the relationships of the erosion curve slope with the $D_{50}$, and the grain size curve slope. In these relationships, the initial slope and the mean grain size $D_{50}$ has a quite strong correlation with $R^{2}=0.86$; other relationships have medium correlation to very weak correlation, with $R^{2}$ of 0.60 to 0.02 . (Figure 12 to Figure 15). The results on the relationship of the critical shear stress and the erosion curve slope in this research have the same trend as results in most previous research (Shafii et al. 2016; Panagiotopoulos et al. 1997). Especially, it can see that the clay content had a great effect on the critical shear stress when the soil has clay content higher than $11 \%$ and cause dramatically with the clay content reach up 50\% as concluded in (Panagiotopoulos et al. 1997). However, the coefficient of determination in (Kimiaghalam et al. 2016) shown that there was no strong correlation between the grain size properties and erosion properties. In that research, the erosion rate was carried out with different densities and clay content, which may be as the reason causing the deference trend of results. To comparing the erosion rate, the erosion rate has to be carried out in the sample physical density. Moreover, the sandclay mixture structure also needs concern as shown in (Das et al. 2019; Barman et al. 2019).

It can find a close relation exists between the erosion rate and the soil grain size when the shear stress increase higher than $5 \mathrm{~Pa}$ as shown Figure 9. Silt I and Silt II groups have sand content increasing the intervals of 5\% from Silt I-01 to Silt II-03 (the highest sand content is 36.6\%). Therefore, Silt II-03 has the 
highest erosion rate among the Silt groups. The four soils of Silt I-01, Silt I-02, Silt I-03, and Silt II-01 have clay contents that decrease in the interval of about $5 \%$ in each soil sample (decrease from $25 \%$ to $10 \%$ ), corresponding to a sand content increase from $4 \%$ to $20 \%$ (see Table 1). Soil erosion curves of those four soils are markedly different, an especially marked difference is observed for soil with water velocity higher than $0.4 \mathrm{~m} / \mathrm{s}$ (the shear stress is higher than $10 \mathrm{~Pa}$ ). The change of erosion rate of Silt I (or four these soil as Silt I-01, Silt I-02, Silt I-03 and Silt II-01) with gradually decreasing 5\% of clay and responding to increase of sand content, is more strongly affected than in Silt II group in which change of silt and sand contents was found. The increasing of the erosion rate of a soil is presented by the initial slope and erosion slope as shown Figure 11). The soil with higher sand content has higher the slope that means the erosion rate increase quickly when the flow shear stress increases.

In the of clay group including $\mathrm{Cl} 01, \mathrm{Cl} 02$, and $\mathrm{Cl} 03$, with clay contents of $36.0 \%, 42.4 \%$, and $70.0 \%$, respectively, and with sand contents less than $2 \%$, the erosion rate of this soil group is the lowest. The $\mathrm{Cl}$ 03 and Silt I-01 (36\% and 25\% clay contents, respectively) have nearly the same erosion value, whereas the erosion rates of $\mathrm{Cl} 01$ and $\mathrm{Cl} 02$ are very small, and therefore might be negligible compared to the erosion rates of Silt I and Silt II soils. This result demonstrates that clay soil with clay contents higher than $40 \%$ might be affected non-significantly in terms of stability against water flow shear stress, which agrees with results reported from earlier studies (Panagiotopoulos 1997; Van Ledden 2004).

\subsection{The relationships of shear strength, soil suction on the critical shear stress}

Figure 16 shows the relationship of the critical shear stress and the erosion slope with the soil strength (the cohesion force, the internal friction angle, and residual suction). Base on that result, a strong correlation can be seen in the relationship between cohesion force and residual suction. The coefficient of determination $R^{2}$ higher than 0.9 in both these relationships, but only about 0.5 in the relationship with friction angle. With the high cohesion force and the residual suction, the critical shear stress has a higher value. In general, of shear strength properties, the high shear strength normally found in the cohesion soil. That trend is also found in this research. Combining with the effects of clay content, it can seem that the soil has a high clay content, having high cohesion force, and then found the high critical shear stress. The cohesion force also had the most effects on the critical shear stress than other geotechnical properties found in (Kimiaghalam 2016). 
The cohesion force and suction are important mechanics geotechnical properties against the shear stress by loading. Base on the result in this paper and previous research on erosion properties, it can see that the shear strength and residual suction are the main factors controlling resistance properties to not only loading but also flow shear stress. Therefore, the shear strength and residual suction can be suggested as main factors for the geotechnical engineer to improve soil and use the shear strength in the protect construction resisting erosion

\subsection{The effects of density on erosion properties}

Figures 22 to 25 show erosion results of 4 soil (Cl 03, Silt I-01, Silt I-03, and Silt II-03) at densities of 13.5 $\mathrm{kN} / \mathrm{m}^{3}, 15 \mathrm{kN} / \mathrm{m}^{3}$ and $16.5 \mathrm{kN} / \mathrm{m}^{3}$. As result in density of $15 \mathrm{kN} / \mathrm{m}^{3}$, the erosion rate is inexplicit when the flow shear stress is low. With higher shear stress (higher 5 Pa for Silt II and $10 \mathrm{~Pa}$ for Silt I and Clay soil), the erosion curve becomes divergence responding to density. After that point, the erosion rate increasing quickly and has a higher value in the soil has the low density. The erosion properties at deference densities are calculated from erosion curves and presented in Table 3.

Table 3. The erosion properties at deference density

\begin{tabular}{|c|c|c|c|c|c|c|c|c|c|c|}
\hline \multirow{3}{*}{\multicolumn{2}{|c|}{ Soil types }} & \multicolumn{9}{|c|}{ The critical shear stress and the erosion curve slope at deference density } \\
\hline & & \multicolumn{3}{|c|}{$\square_{c}$} & \multicolumn{3}{|c|}{$K_{i}$} & \multicolumn{3}{|c|}{$K$} \\
\hline & & $\begin{array}{c}1.35 \\
\mathrm{kN} / \mathrm{m}^{3}\end{array}$ & $\begin{array}{c}1.5 \\
\mathrm{kN} / \mathrm{m}^{3}\end{array}$ & $\begin{array}{c}1.65 \\
\mathrm{kN} / \mathrm{m}^{3}\end{array}$ & $\begin{array}{c}1.35 \\
\mathrm{kN} / \mathrm{m}^{3}\end{array}$ & $\begin{array}{c}1.5 \\
\mathrm{kN} / \mathrm{m}^{3}\end{array}$ & $\begin{array}{c}1.65 \\
\mathrm{kN} / \mathrm{m}^{3}\end{array}$ & $\begin{array}{c}1.35 \\
\mathrm{kN} / \mathrm{m}^{3}\end{array}$ & $\begin{array}{c}1.5 \\
\mathrm{kN} / \mathrm{m}^{3}\end{array}$ & $\begin{array}{c}1.65 \\
\mathrm{kN} / \mathrm{m}^{3}\end{array}$ \\
\hline $\mathrm{Cl03}$ & NT01 & 2.5 & 4.5 & 11.5 & 2.9 & 1.5 & & 8.3 & 4.3 & 2.8 \\
\hline Silt I-01 & NT 03 & 1.0 & 1.5 & 2.3 & 6.7 & 3.9 & 1.2 & 27.1 & 4.8 & 5.4 \\
\hline Silt I-03 & HB21 & 1.0 & 1.0 & 2.7 & 30.5 & 11.2 & 4.1 & 55.3 & 25.3 & 20.7 \\
\hline Silt II-03 & $\mathrm{XC}$ & 0.7 & 0.9 & 0.9 & 32.6 & 28.8 & 5.5 & 43.5 & 26.9 & 26.5 \\
\hline
\end{tabular}

Figure 26 shows the respective critical shear stresses for Cl 03, Silt I-01, Silt I-03, and Silt II-03 against dry density. In general, the critical shear stress increase with the increase of density. The Cl 03, Silt I-01, and Silt I-03 soils obtain quite different critical shear stresses at different dry densities, whereas the critical shear stress is not markedly different at different dry densities for Silt II-03 with clay contents of $10 \%$. When the dry density is low (at $13.5 \mathrm{kN} / \mathrm{m}^{3}$ ), the critical shear stress is small and nearly constant with changing grain size in the silt group. At a high dry density $\left(16.5 \mathrm{kN} / \mathrm{m}^{3}\right)$, the critical shear stress increases concomitantly with increasing clay contents.

Figure 27 shows the relationship of density and the initial slope of the erosion curve. For all soils, the slope of the erosion curve decreases when the soil density increase. And the soil with high sand content has a 
higher slope, the slope of the erosion curve decrease from Silt II-03; Silt I-03; Silt I-01; Cl 03, respectively. These results show that the erosion rate will increase quickly in the soil has low density and high sand content

\subsection{Characteristics of the soil surface during erosion}

Different behaviors of silt soils and clay soils are recognizable from images of soil particle movement during soil erosion tests conducted in the laboratory (Figure 28 and 29). For this study, the silt soil groups (Silt I and II) are considered non-cohesive. Particularly, no cohesion exists between the soil particles for Silt II group soils. Each soil particle is independent of the soil particle. Therefore, each particle is removed separately by water flow from the soil-water interface. Figure 28 (left) shows a surface of Silt II-03 after completion of 1-mm erosion. The surface is quite smooth. Most soil particles in the protruding soil core were easily swept away by the water. Silt I-03, which has a higher fines content (70\% silt and $15 \%$ clay), also has a smoothly eroded surface, although it is less smooth than that of Silt II-03, which has a lower fines content (53.4\% silt and 10\% clay). A notable difference is apparent in the images of the Clay group's erosion (Figure 29). Because of the high cohesiveness between soil particles, which tend to bind together (aggregate) to form large aggregate particles, the soil is more difficult to move. At the high water velocity, the soil was removed in aggregate particles, rather more markedly than in individual particles, as in noncohesive soil. Finally, the surface erosion of the clays is not smooth, as presented in Figure 29. As the discussion in (Das et al. 2019; Barman et al. 2019), the soil has a clay content of about 10\%, the network caging between clay and sand was not possible, enhancing the erosion process. When the clay increases up to $25-30 \%$, the mode of erosion changes from particles-by-particles to chunk-by-chunk. The influence of ejection and sweep decreases, increasing the soil erosion rate in the soil has high clay content.

\section{Conclusions}

This paper focus to evaluate the erosion properties of soil collected from the banks of the Red River, and assess the influences of geotechnical properties as grain size, density, shear strength, and residual suction. In general, the soil erosion rate decreases concomitantly with increasing clay content, dry density, and shear strength, whereas the critical shear stress increases concomitantly respectively. Some specific conclusions were obtained from the test results as following:

The change of clay content has a strong effect both on the critical shear stress and the erosion curve. In the mixture soil, the difference of $5 \%$ clay content enough to build great effects on the erosion rate curve. The 
erosion rate of the soil with high clay content (more than $40 \%$ ) is very low and might be affected nonsignificantly by the change of grain size content. The change of sand content has a strong effect on the erosion rate and slope of the erosion curve. The soil with higher sand content has a higher slope and the soil erosion rate increase quickly.

The density has a close relationship with the critical shear stress and erosion slope. The soil with higher density has higher critical shear stress; The erosion rate increase quickly in the soil has a low density and high sand content.

Both the cohesion force and soil suction have a strong effect and have a linear correlation with the critical shear stress. The relationship of the critical shear stress with the friction angle and the shear strength with the slope of erosion curves is a medium or weak correlation.

Base on the result in this research, the clay content, and dry density is a first important factor need considered. These properties have greatly affected other properties, including the shear strength, suction, and the critical shear strength mention in this paper. Here also suggest use shear strength and residual suction as the major factors controlling the resistance soil properties and erosion.

\section{References}

Abidin RZ, Sulaiman MS, Yusoff N (2017) Erosion risk assessment: A case study of the Langat River bank in Malaysia. International Soil and Water Conservation Research 5(1):26-35. https://doi.org/10.1016/j.iswcr.2017.01.002

Ahmad MF, Dong P, Mamat M, Wan Nik WB, Mohd MH (2011) The Critical Shear Stresses for Sand and Mud Mixture. Applied Mathematical Sciences 5(2):53-71

Badr HM, Habib MA, Ben-Mansour R, Said SA (2002) Effect of flow velocity and particle size on erosion in a pipe with sudden contraction. InProceedings of the 6th Saudi Engineering Conference 2002 Dec 5:79-95

Barman K, Roy S, Das VK, Debnath K (2019) Effect of clay fraction on turbulence characteristics of flow near an eroded bank. Journal of hydrology 571:87-102. https://doi.org/10.1016/j.jhydrol.2019.01.061

Benamar A, Karoui T, Bennabi A, Seghir A, Wang H (2012) Influence of fine particles on internal erosion of sandy Soils. ICSE6 Paris - August 27-31, 2012:1097-1104.

Benseghier Z, Cuéllar P, Luu LH, Delenne JY, Bonelli S, Philippe P (2020) Relevance of free jet model for soil erosion by impinging jets. Journal of Hydraulic Engineering 146(1):04019047. https://doi.org/10.1061/(ASCE)HY.1943-7900.0001652

Berlamont J, Ockenden M, Toorman E, Winterwerp J (1993) The characterisation of cohesive sediment properties. Coastal Engineering 21(1-3):105-128. https://doi.org/10.1016/0378-3839(93)90047-C

Berlamont J, Ockenden M, Toorman E, Winterwerp J (1993) The characterisation of cohesive sediment properties. Coastal Engineering 21(1-3):105-28. https://doi.org/10.1016/0378-3839(93)90047-C

Bo NI, Wu SQ, Tan YF, Xie XH, Jun YA, Yan ZM, Geng YQ (2011) Coupling effect of seepage flow and river flow on bank failure. Journal of Hydrodynamics 23(6):834-840. https://doi.org/10.1016/S10016058(10)60183-7 
Boudreaux JP (2012) Shear strength evaluation of an erosional soil system at Fourchon Beach. LSU Master's Theses. Louisiana State University and Agricultural and Mechanical College

Briaud JL (2008) Case Histories in Soil and Rock Erosion: Woodrow Wilson Bridge, Brazos River Meander, Normandy Cliffs, and New Orleans Levees. J. Geotech. Geoinviron. Eng., ASCE 134(10):1424-1447. https://doi.org/10.1061/(ASCE)1090-0241(2008)134:10(1425)

Briaud JL, Chen HC, Kwak KW, Han SW, Ting FC (2001b) Multiflood and multilayer method for scour rate prediction at bridge piers. Journal of Geotechnical and Geoenvironmental Engineering 127(2):11425. https://doi.org/10.1061/(ASCE)1090-0241(2001)127:2(114)

Briaud JL, Chen HC, Li Y, Nurtjahyo P (2004) SRICOS-EFA method for complex piers in fine-grained soils. Journal of geotechnical and geoenvironmental engineering 130(11):1180-1191. https://doi.org/10.1061/(ASCE)1090-0241(2004)130:11(1180)

Briaud JL, Ting FC, Chen HC, Cao Y, Han SW, Kwak KW (2001a) Erosion function apparatus for scour rate predictions. Journal of Geotechnical and Geoenvironmental Engineering 127(2):105-13. https://doi.org/10.1061/(ASCE)1090-0241(2001)127:2(105)

Briaud JL, Ting FC, Chen HC, Gudavalli R, Perugu S, Wei G (1999) SRICOS: Prediction of scour rate in cohesive soils at bridge piers. Journal of Geotechnical and Geoenvironmental Engineering 125(4):237246. https://doi.org/10.1061/(ASCE)1090-0241(1999)125:4(237)

Couper P (2003) Effects of silt - clay content on the susceptibility of river banks to subaerial erosion. Geomorphology 56:95-108. https://doi.org/10.1016/S0169-555X(03)00048-5

Darby SE, Rinaldi M, Dapporto S (2007) Coupling simulations of fluvial erosion and mass wasting for $\begin{array}{lllll}\text { cohesive river banks. Journal of Geophysical Research } 112 & \text { (F03022):1-15. }\end{array}$ https://doi.org/10.1029/2006JF000722

Das VK, Roy S, Barman K, Chaudhuri S, Debnath K (2019) Study of clay-sand network structures and its effect on river bank erosion: an experimental approach. Environmental Earth Sciences 78(20):1-8. 10.1007/s12665-019-8613-5

Fattet M, Fu Y, Ghestem M, Ma W, Foulonneau M, Nespoulous J, Le Bissonnais Y, Stokes A (2011) Effects of vegetation type on soil resistance to erosion: Relationship between aggregate stability and shear strength. Catena 87(1):60-69. https://doi.org/10.1016/j.catena.2011.05.006

Goharrokhi M. Effect of hydraulic shear stress on the banks of the Red River. Master thesis 2015. The University of Manitoba. Winnipeg, Manitoba, Canada

Grabowski RC, Droppo IG, Wharton G (2011) Erodibility of cohesive sediment: The importance of sediment properties. Earth-Science Reviews 105(3-4):101-20. 10.1016/j.earscirev.2011.01.008

Jacobs W, Le Hir P, Van Kesteren W, Cann P. Erosion (2011) Erosion Threshold of Sand-Mud Mixtures. Continental Shelf Research 31(10):S14-S25. https://doi.org/10.1016/j.csr.2010.05.012

Jepsen R, Roberts J, Lick W (1997) Effects of Bulk Density on Sediment Erosion Rates Water. Air and Soil Pollution 99(1):21-31

Jianfar, A (2014) Evaluation of erosion rates and their impact on riverbank stability. Master Thesis. Master of Science, The University of Manitoba

Julien PY (2002) River mechanics. Cambridge University Press. ISBN-13 978-0-511-07587-2.

Kimiaghalam N, Clark SP, Ahmari H (2016) An experimental study on the effects of physical, mechanical, and electrochemical properties of natural cohesive soils on critical shear stress and erosion rate. International Journal of Sediment Research 31(1):1-15. https://doi.org/10.1016/j.ijsrc.2015.01.001

Léonard J, Richard G (2004) Estimation of runoff critical shear stress for soil erosion from soil shear strength. Catena 57(3):233-249. https://doi.org/10.1016/j.catena.2003.11.007

Li Q, Wang L, Ma X, Nie R. (2020). Experimental study of effects of riverbed composition on the riverbank erosion process. In Proceedings of the Institution of Civil Engineers-Water Management 173(4):199-207

Lick W, McNeil J (2001) Effects of sediment bulk properties on erosion rates. The Science of the Total Environment 266(1-3):41-48. 10.1016/s0048-9697(00)00747-6

Mitchener H, Torfs H (1996) Erosion of mud/sand mixtures. Coastal engineering 29(1-2):1-25. https://doi.org/10.1016/S0378-3839(96)00002-6

Mobley TJ (2009) Erodibility testing of cohesion soil. Master thesis. Auburn, Alabama 
Montoya BM, Do J, Gabr MM (2018) Erodibility of microbial induced carbonate precipitation-stabilized sand under submerged impinging jet. In IFCEE 2018: 19-28. https://doi.org/10.1061/9780784481592.003

Panagiotopoulos I, Voulgaris G, Collins MB (1997) The influence of clay on the threshold of movement on fine sandy beds. Coastal Engineering 32(1):19-43. https://doi.org/10.1016/S0378-3839(97)00013-6

Patsinghasanee S, Kimura I, Shimizu Y, Nabi M (2018) Experiments and modelling of cantilever failures for cohesive riverbanks. Journal of Hydraulic Research 56(1):76-95. https://doi.org/10.1080/00221686.2017.1300194

Regazzoni PL, Marot D. (2011). Investigation of interface erosion rate by Jet Erosion Test and statistical analysis. European Journal of Environmental and Civil Engineering 15(8):1167-1185. https://doi.org/10.1080/19648189.2011.9714847

Roberts J, Jepsen R, Gotthard D, Lick W (1998) Effects of particle size and bulk density on erosion of quartz particles. Journal of Hydraulic Engineering, ASCE 24(12):1261-1267. https://doi.org/10.1061/(ASCE)0733-9429(1998)124:12(1261)

Roy S, Barman K, Das VK, Debnath K, Mazumder BS (2020). Experimental Investigation of Undercut Mechanisms of River Bank Erosion Based on 3D Turbulence Characteristics. Environmental Processes 7(1):341-366

Shafii I, Briaud J, Chen H, Shidlovskaya A (2016) Relationship between soil erodibility and engineering properties. In: ICSE 2016 (8th International Conference on Scour and Erosion), 12-15 September 2016, Oxford, UK. http://eprints.hrwallingford.com/id/eprint/1144

Simon A, Pollen-Bankhead N, Thomas RE (2011) Development and application of a deterministic bank stability and toe erosion model for stream restoration. Stream restoration in dynamic fluvial systems: Scientific Approaches, Analyses, and Tools, American Geophysical Union, Geophysical Monograph 194:453-474

Toan DT (2014) Assessment of riverbank stability - the perspectives of unsaturated soils and erosion function. Doctoral Dissertation, September 2014, Ibaraki University

Toan DT, Duc DM (2019). Riverbank Stability Assessment under River Water Level Changes and Hydraulic Erosion. Water 11(12):2598. https://doi.org/10.3390/w11122598

Van Ledden M, Van Kesteren WG, Winterwerp JC (2004) A conceptual Framework for the Erosion Behavior of Sand-Mud Mixtures. Continental Shelf Research 24(1):1-11. https://doi.org/10.1016/j.csr.2003.09.002

Yong GL, Robert E, Thomas YO, Simon A, Blair P, Greimann KW (2014) Modeling of multilayer cohesive bank erosion with a coupled bank stability and mobile-bed mode. Geomorphology 243:116-129. https://doi.org/10.1016/j.geomorph.2014.07.017

Yu MH, Wei HY, Wu SB (2015) Experimental study on the bank erosion and interaction with near-bank bed evolution due to fluvial hydraulic force. International Journal of Sediment Research 30(1):81-89. https://doi.org/10.1016/S1001-6279(15)60009-9

\section{Figure Captions}

Fig. 1 Suction curves and fitting parameters

Fig. 2 Red River flowing through the Hanoi area

Fig. 3 Grain size distribution curves

Fig. 4 Plasticity chart for soil specimens used for laboratory experiments

Fig. 5 Configuration of soil erosion testing apparatus 
Fig. 6 The photograph of erosion test apparatus, and cylindrical mould for soil compacting samples

Fig. 7 Soil protruding $1 \mathrm{~mm}$ sample before starting water flow (Briaud 2008)

Fig. 8 Relation of soil erosion rate and water shear stress (Briaud 2008)

Fig. 9 Erosion rate by water velocity (left) and shear stress (right) at a dry density of $15.0 \mathrm{kN} / \mathrm{m}^{3}$

Fig. 10 Critical shear stress (CSS) versus grain size

Fig. 11 Erosion curve slope versus sand content

Fig. 12 Critical shear stress versus mean grain size diameter

Fig. 13 Slope of erosion curve versus mean grain size diameter

Fig. 14 Critical shear stress (CSS) versus grain size slope

Fig. 15 Erosion curve slope versus grain size slope

Fig. 16 Critical shear stress (CSS) versus cohesion force

Fig. 17 Erosion curver slope versus cohesion force

Fig. 18 Critical shear stress versus internal friction angle

Fig. 19 Erosion curve slope versus cohesion force

Fig. 20 Critical shear stress versus residual suction

Fig. 21 Erosion curve slope versus residual suction

Fig. 22 Erosion rate of $\mathrm{Cl} 03$

Fig. 23 Erosion rate of Silt I-01

Fig. 24 Erosion rate of Silt I-03

Fig. 25 Erosion rate of Silt II-03

Fig. 26 Critical shear stress at different dry densities

Fig. 27 The initial slope of erosion curve at different dry densities

Fig. 28 Surface erosion in silt soils (Silt II-03 at left, Silt I-03 at right)

Fig. 29 Surface erosion in Clay soil ( $\mathrm{Cl} 01$ after $5 \mathrm{~min}$ and $10 \mathrm{~min}$ at a water velocity of $0.5 \mathrm{~m} / \mathrm{s}$ ) 
Figures

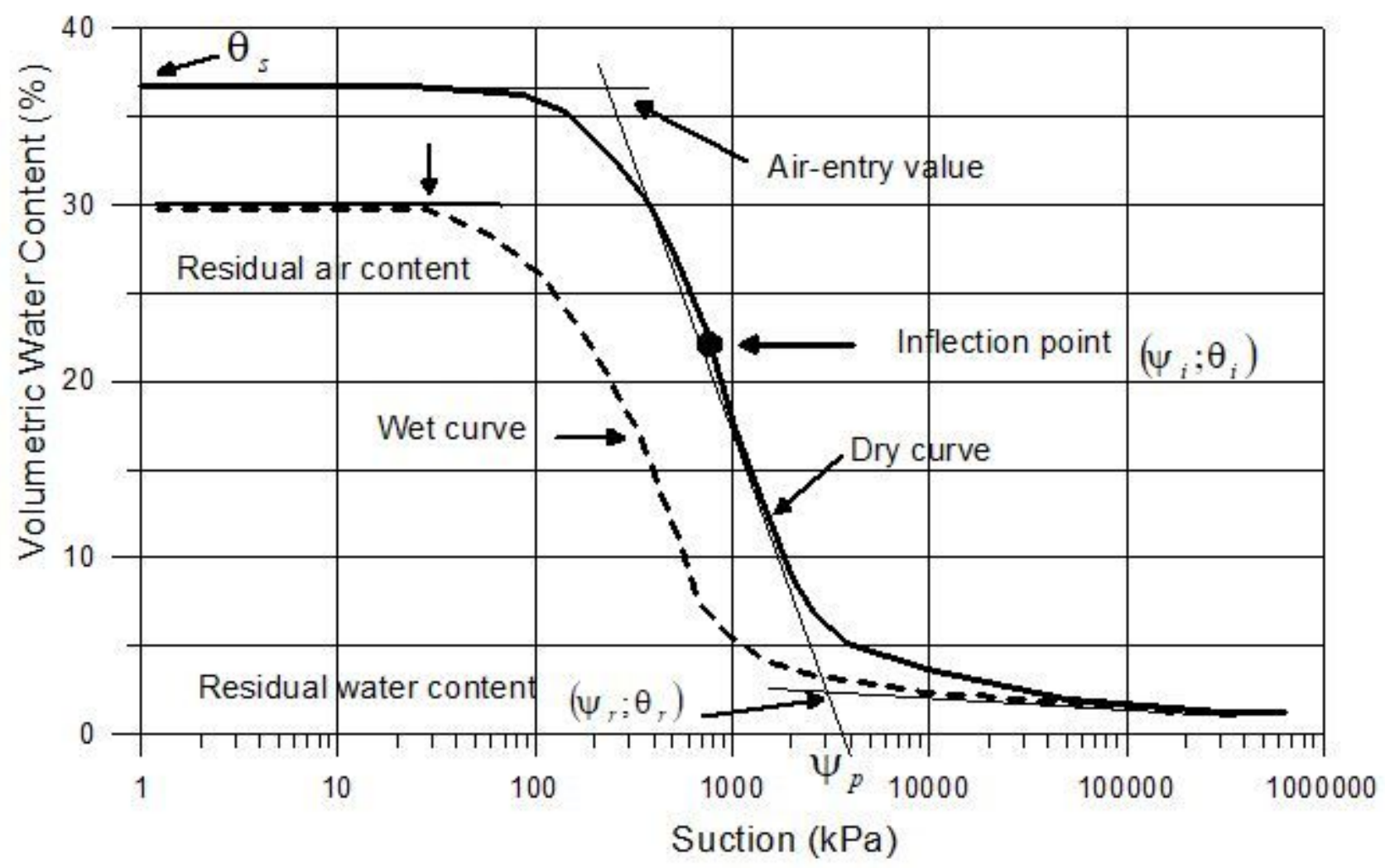

Figure 1

Suction curves and fitting parameters 


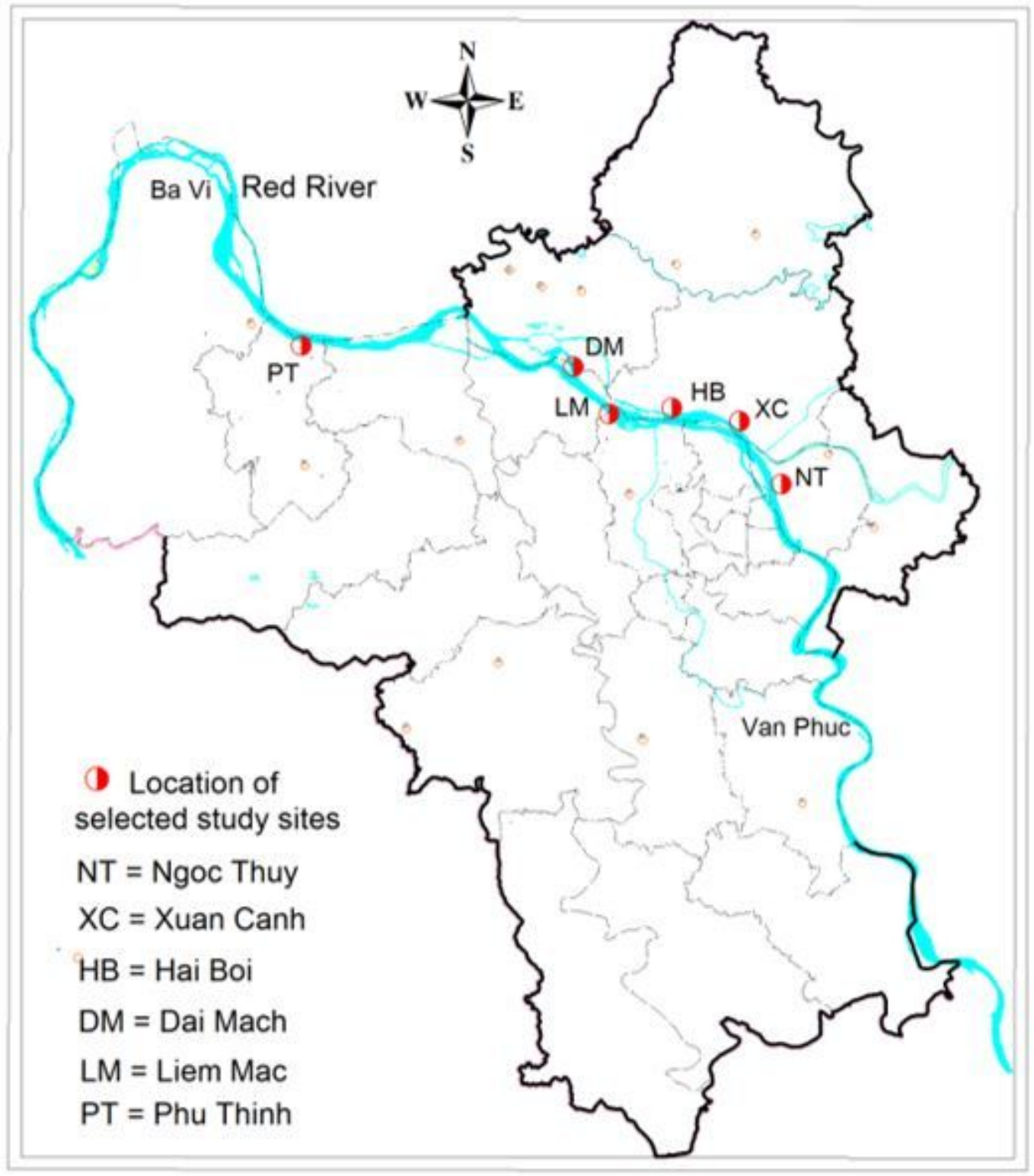

\section{Figure 2}

Red River flowing through the Hanoi area Note: The designations employed and the presentation of the material on this map do not imply the expression of any opinion whatsoever on the part of Research Square concerning the legal status of any country, territory, city or area or of its authorities, or concerning the delimitation of its frontiers or boundaries. This map has been provided by the authors. 


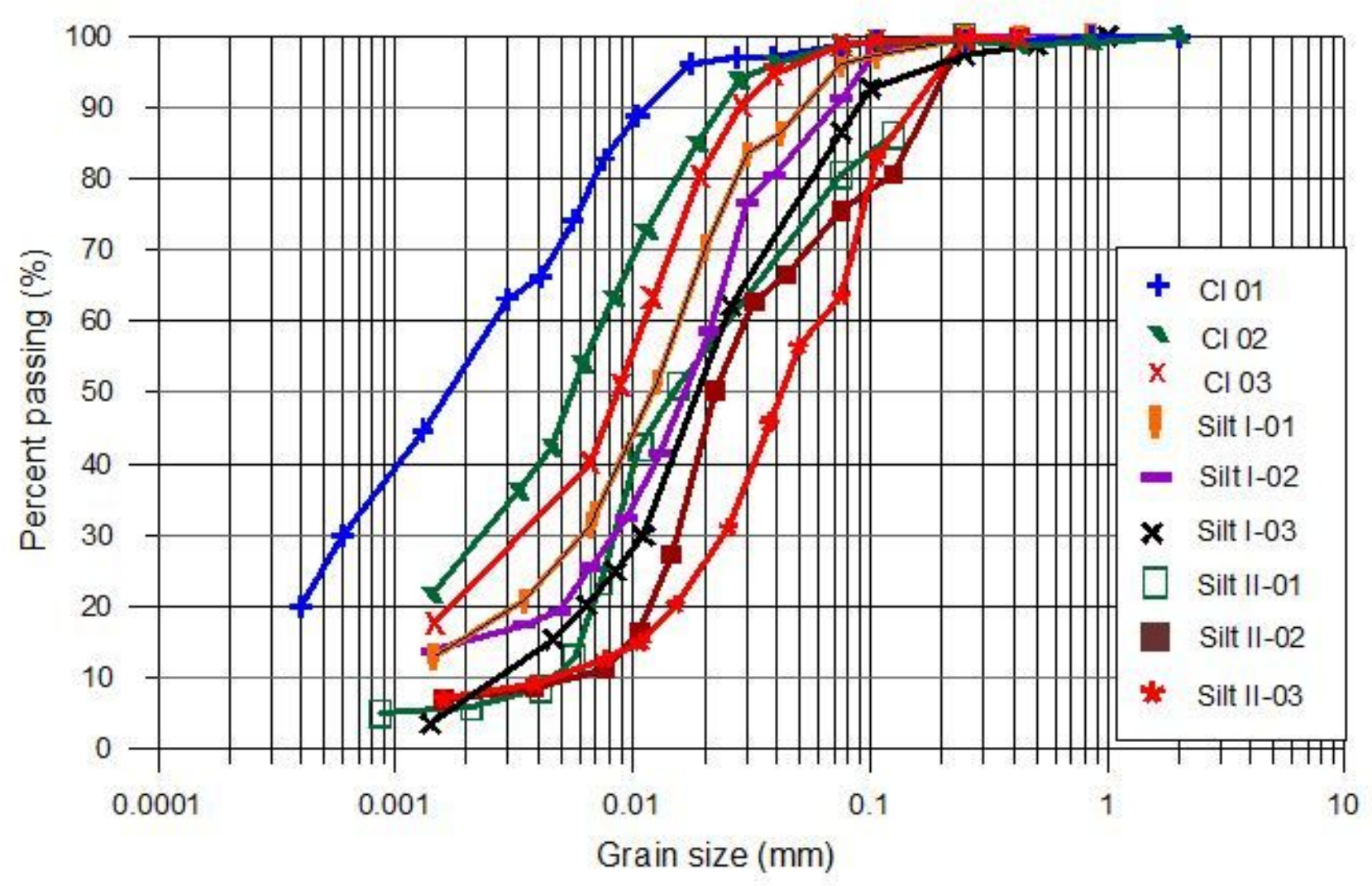

Figure 3

Grain size distribution curves 


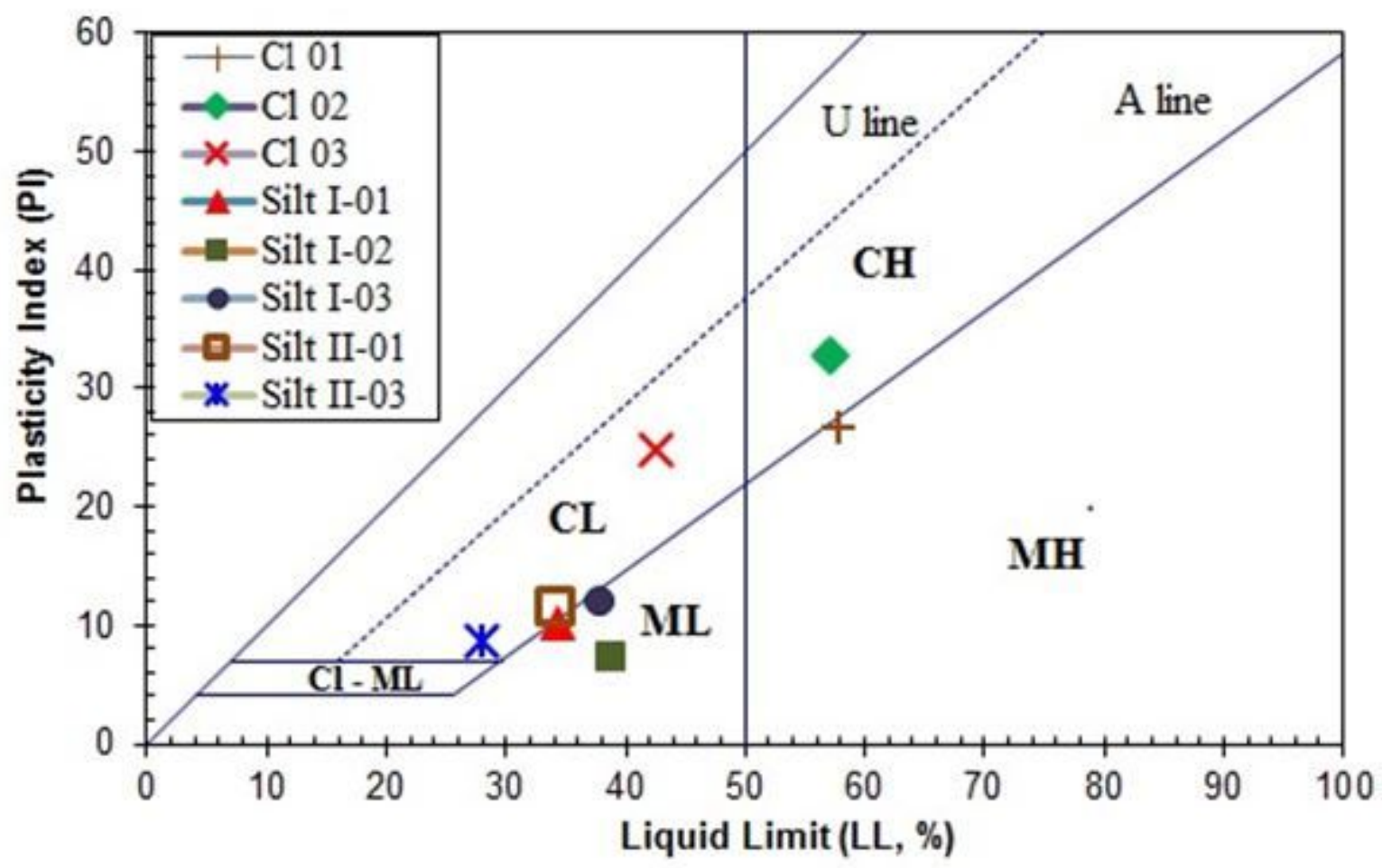

Figure 4

Plasticity chart for soil specimens used for laboratory experiments 


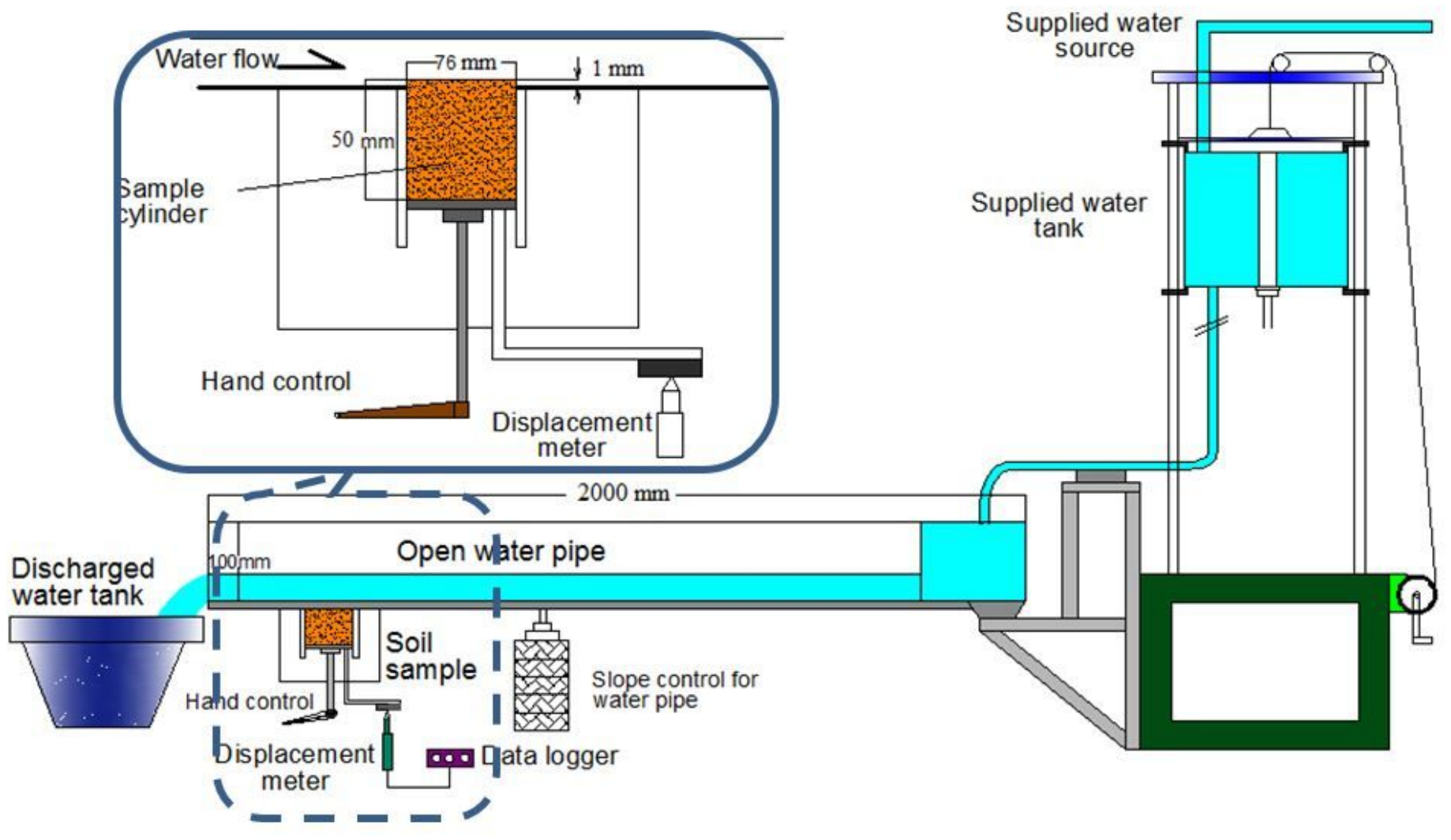

Figure 5

Configuration of soil erosion testing apparatus 

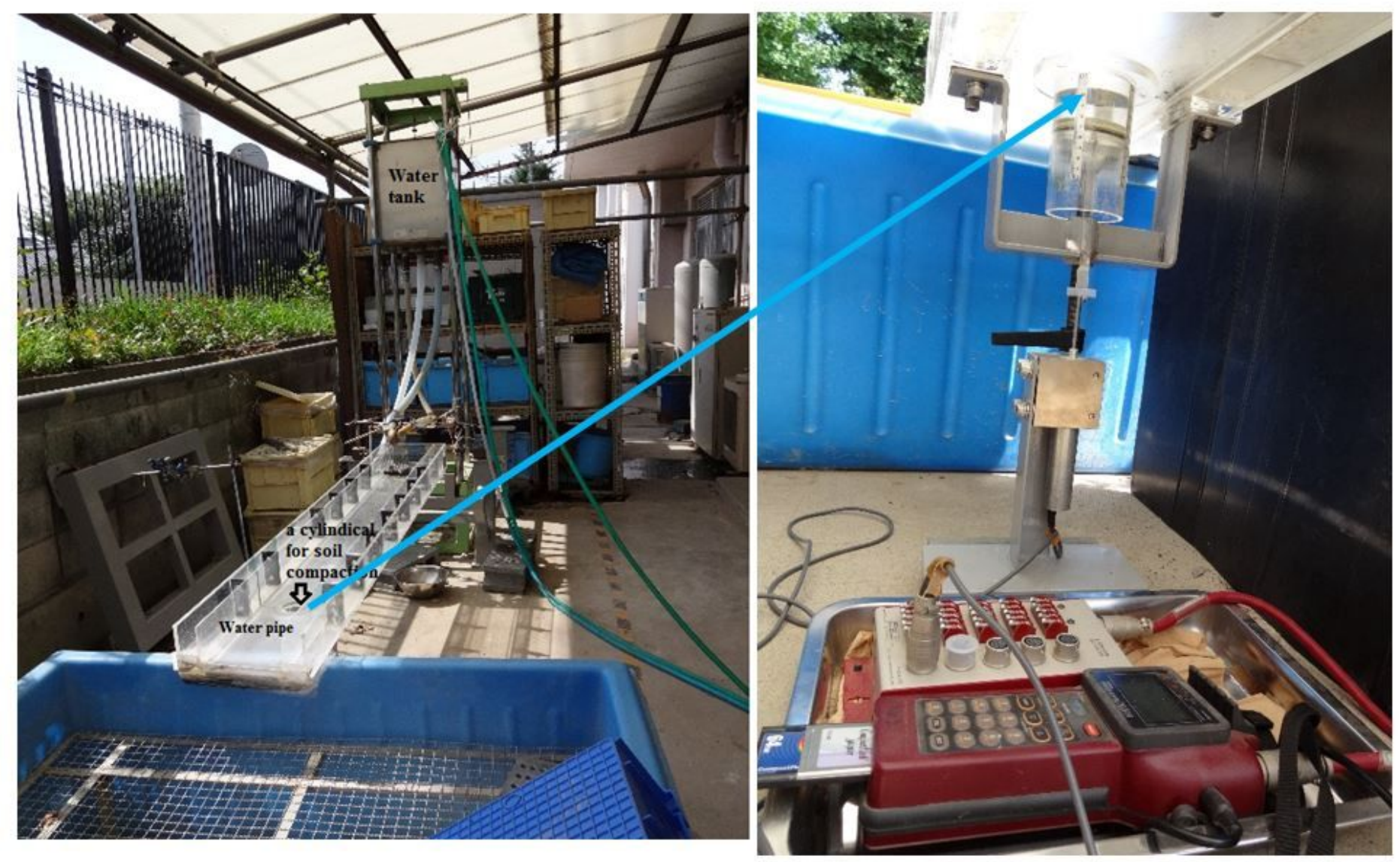

Figure 6

The photograph of erosion test apparatus, and cylindrical mould for soil compacting samples 

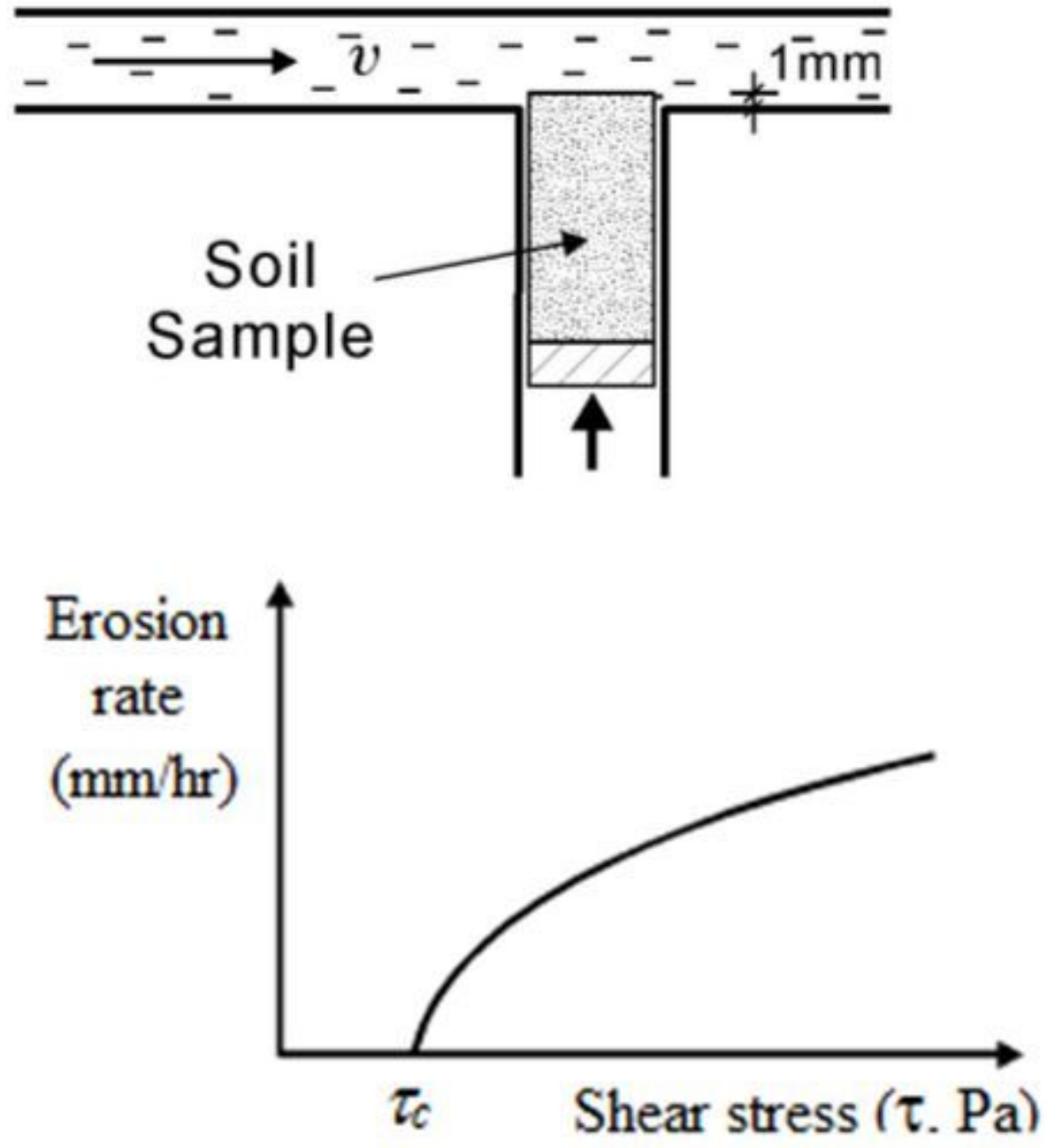

Figure 7

Soil protruding $1 \mathrm{~mm}$ sample before starting water flow (Briaud 2008) 


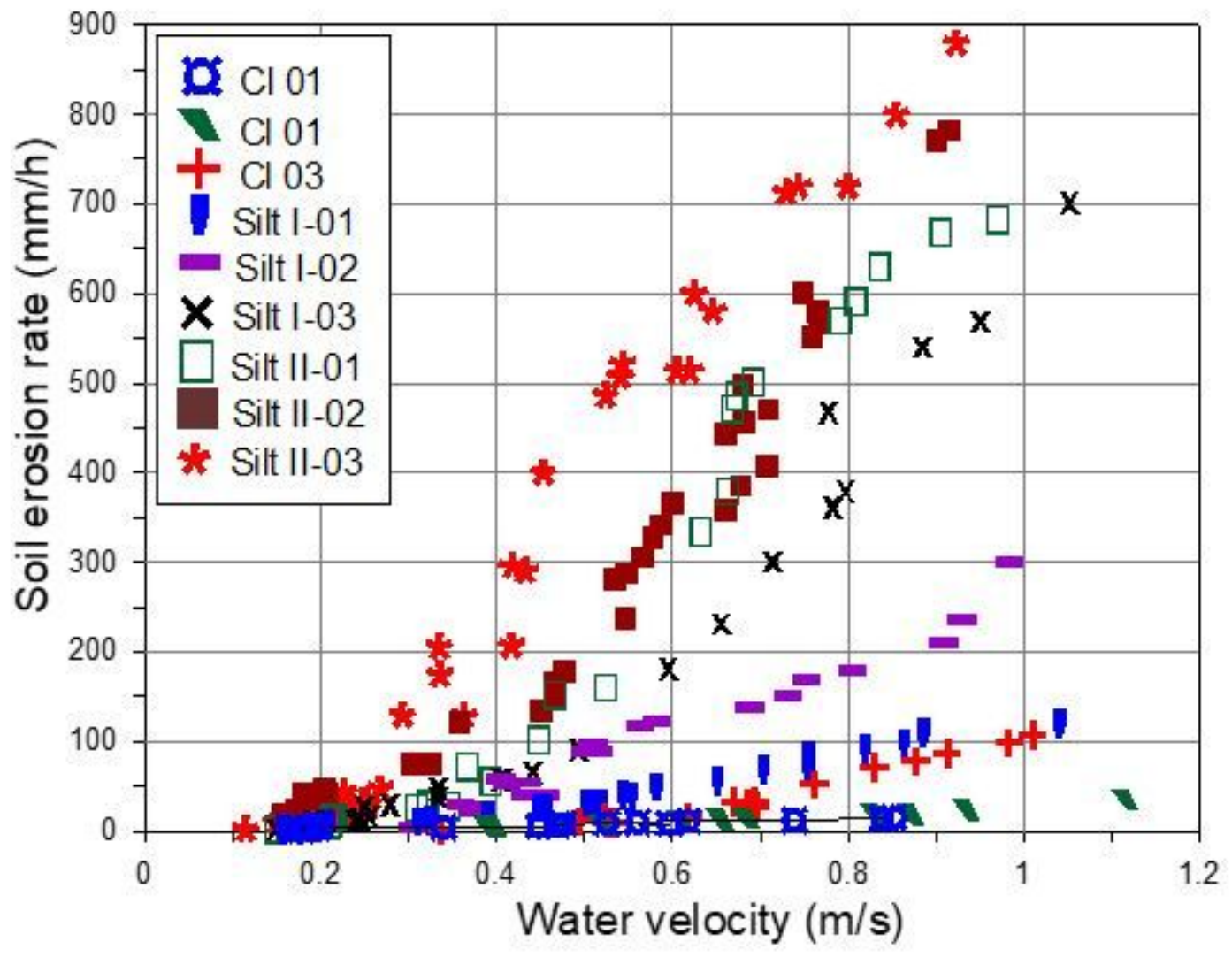

Figure 8

Relation of soil erosion rate and water shear stress (Briaud 2008) 


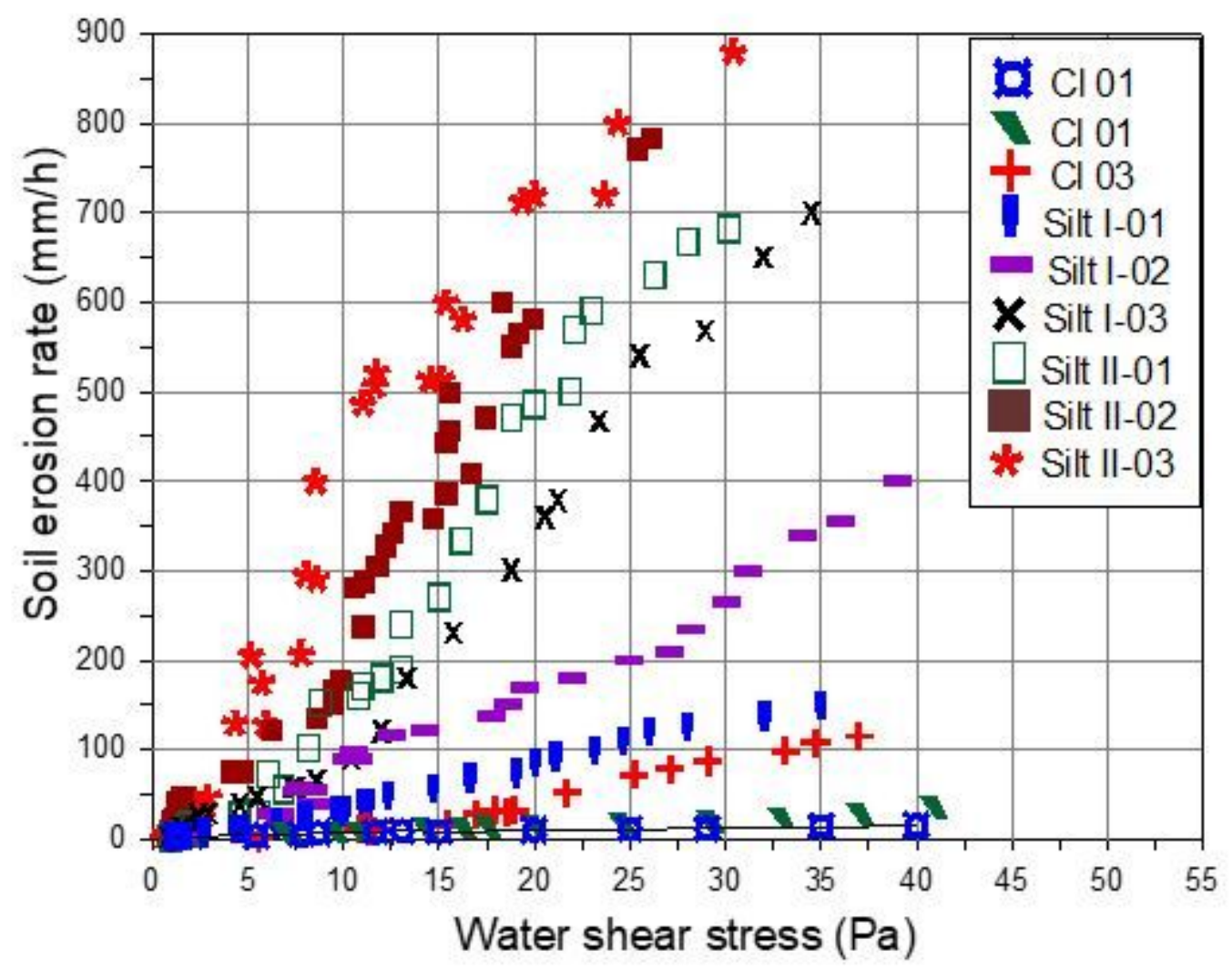

Figure 9

Erosion rate by water velocity (left) and shear stress (right) at a dry density of $15.0 \mathrm{kN} / \mathrm{m} 3$ 


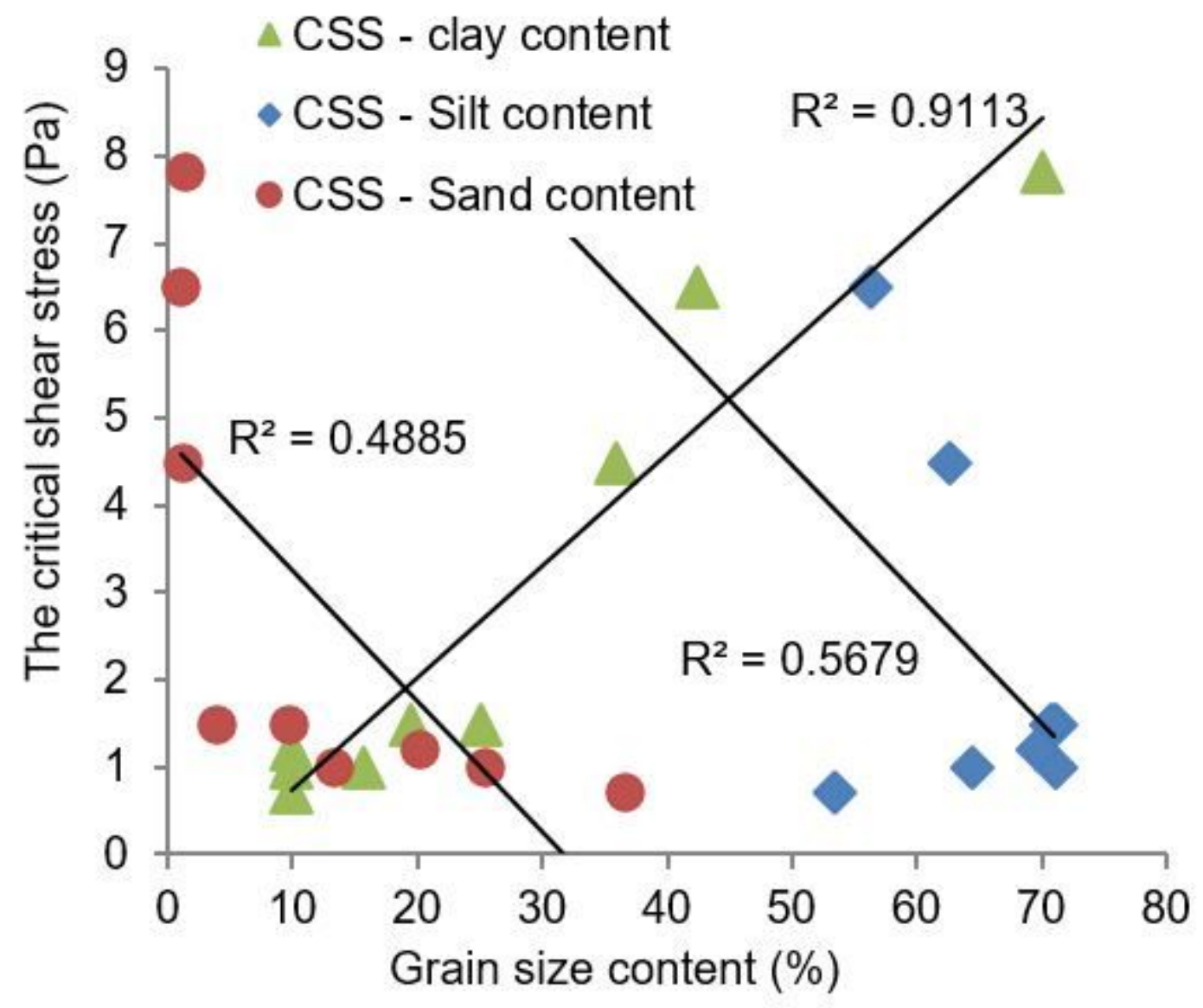

Figure 10

Critical shear stress (CSS) versus grain size 


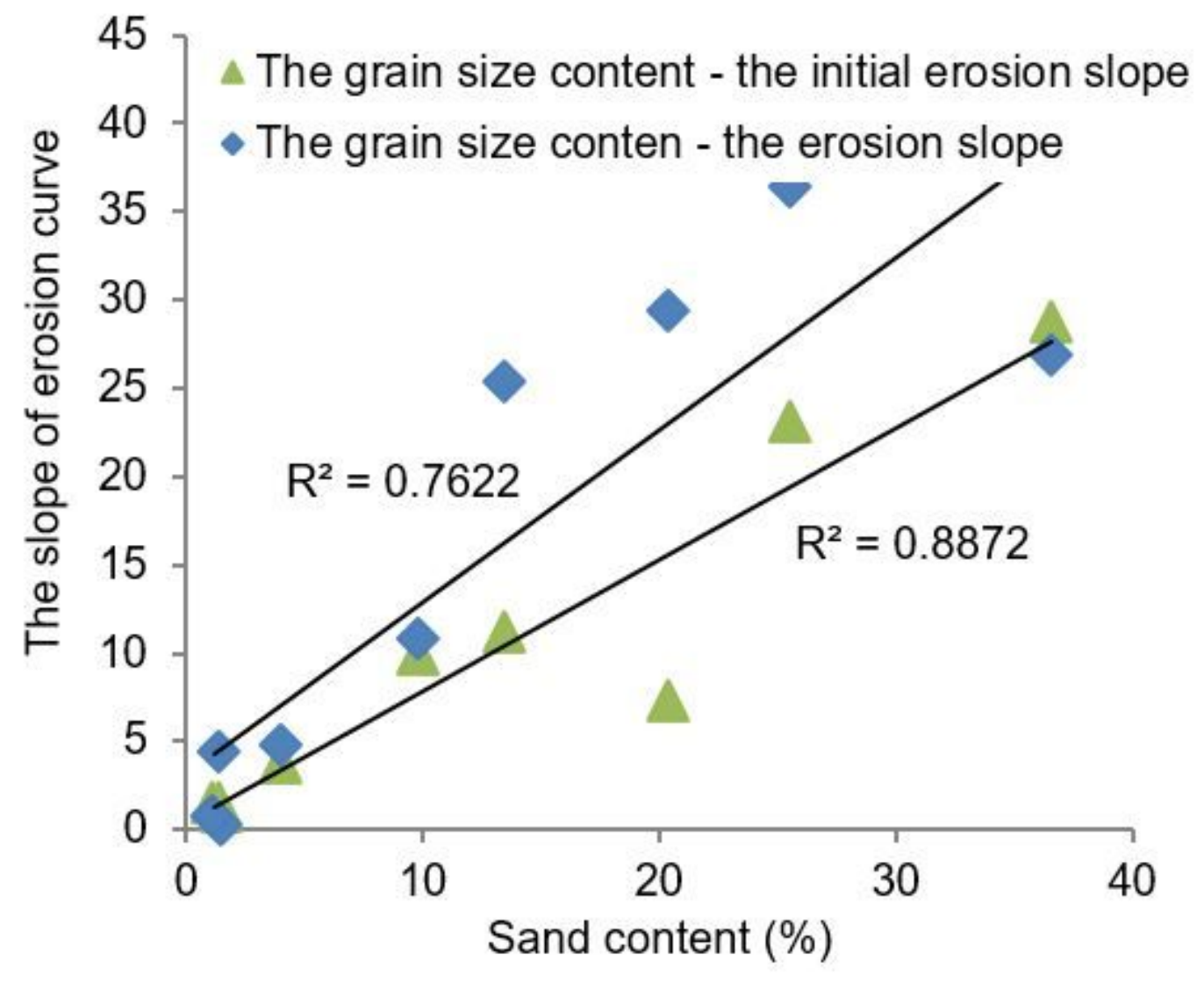

Figure 11

Erosion curve slope versus sand content 


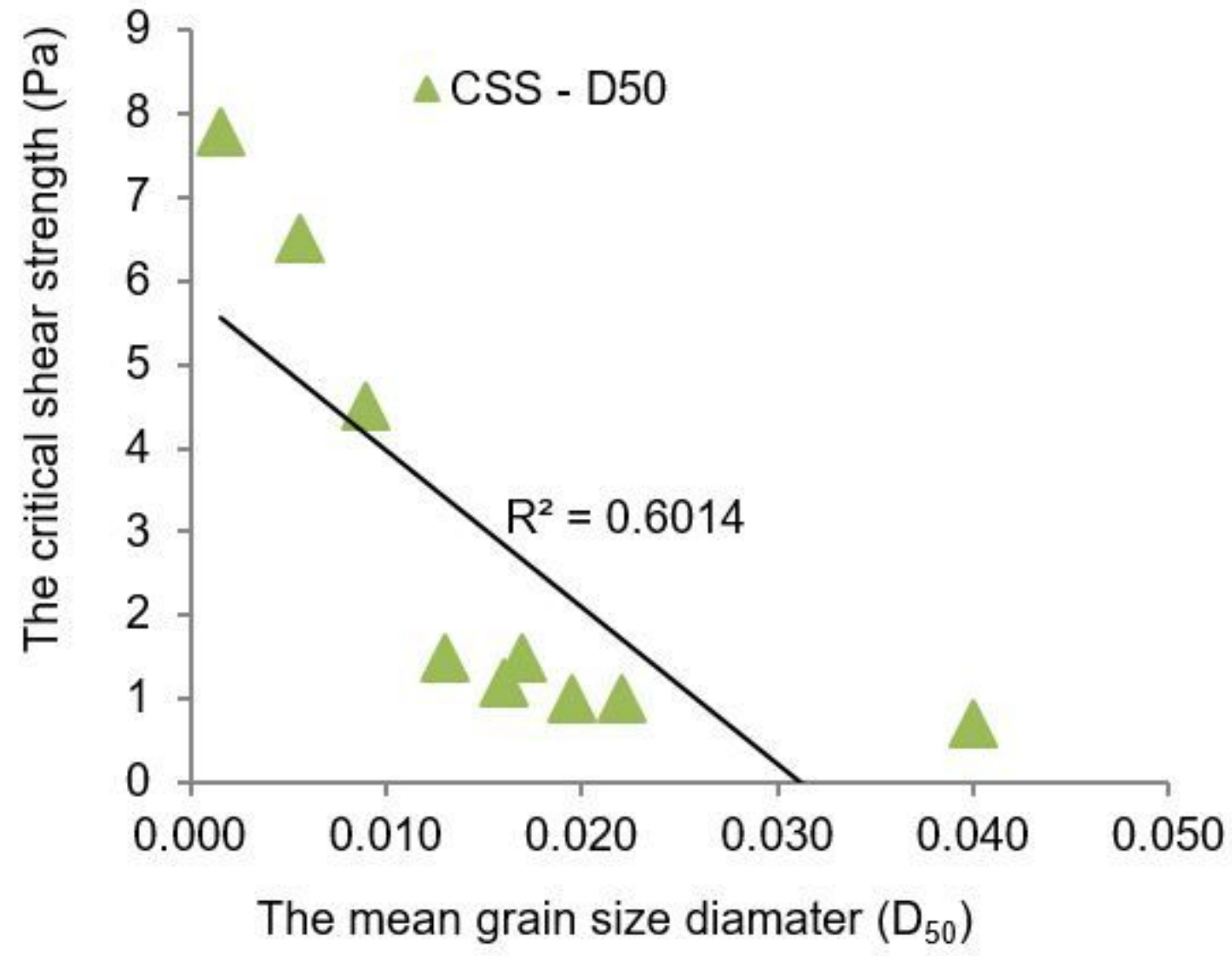

Figure 12

Critical shear stress versus mean grain size diameter 


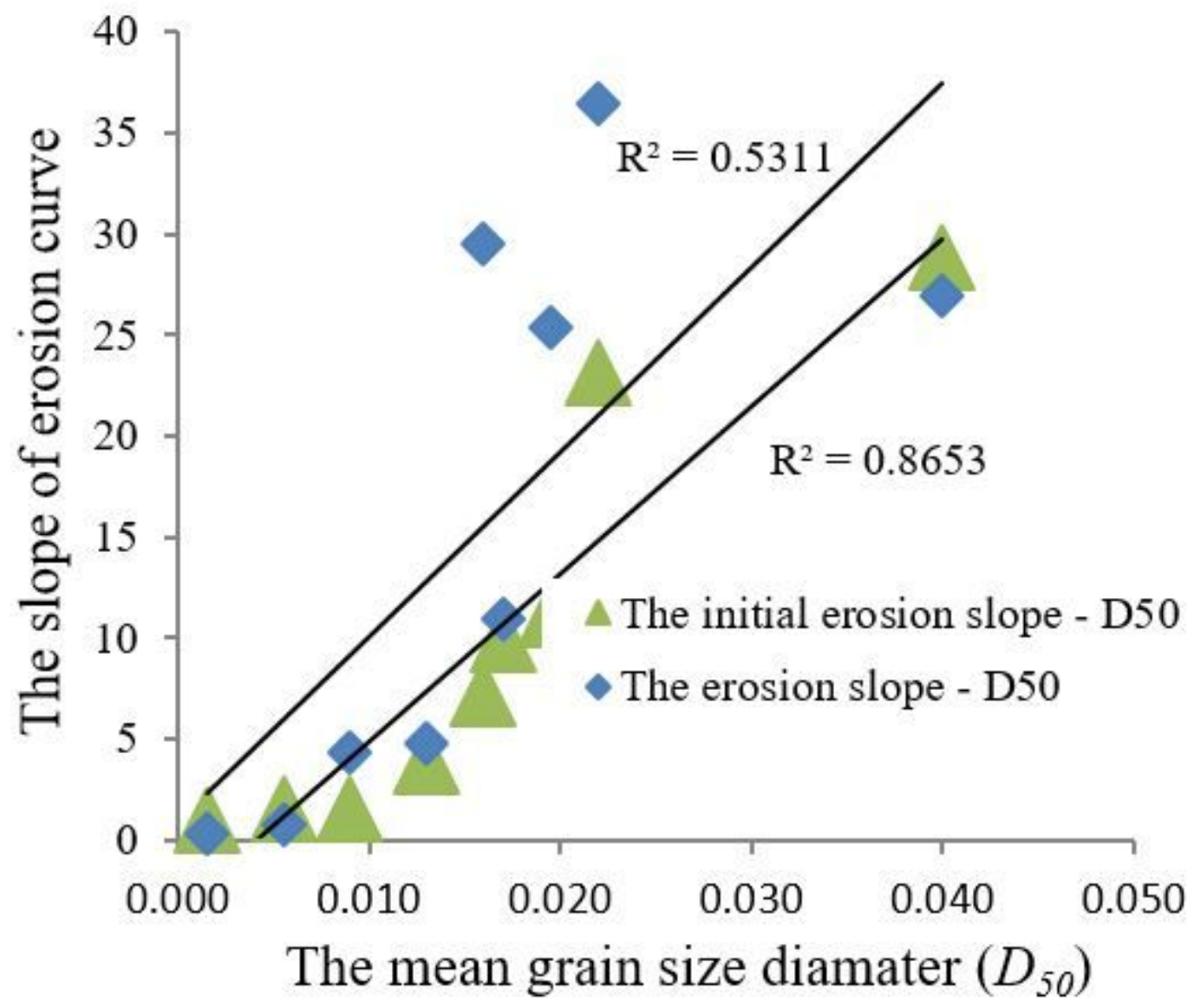

Figure 13

Slope of erosion curve versus mean grain size diameter 


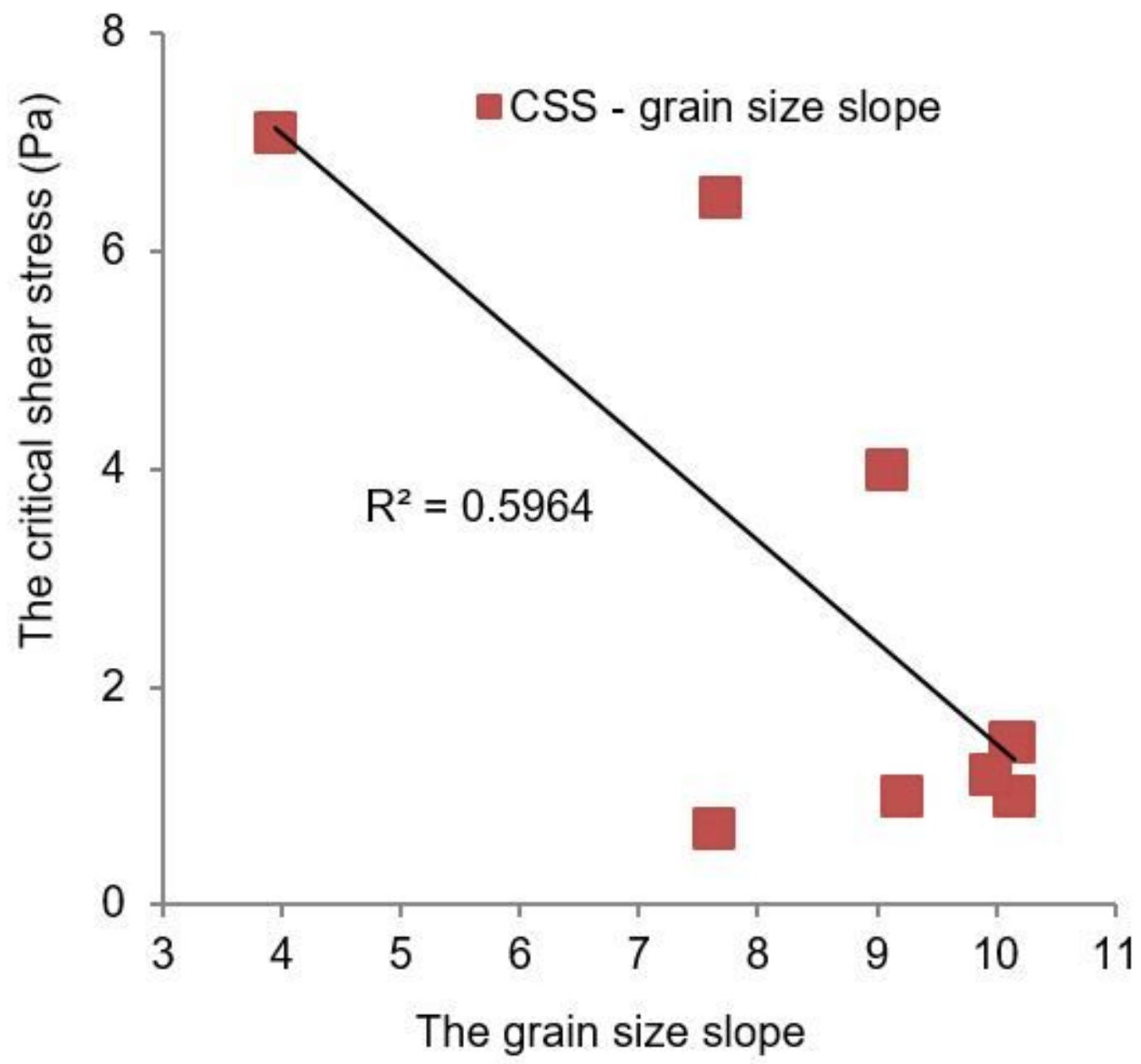

Figure 14

Critical shear stress (CSS) versus grain size slope 


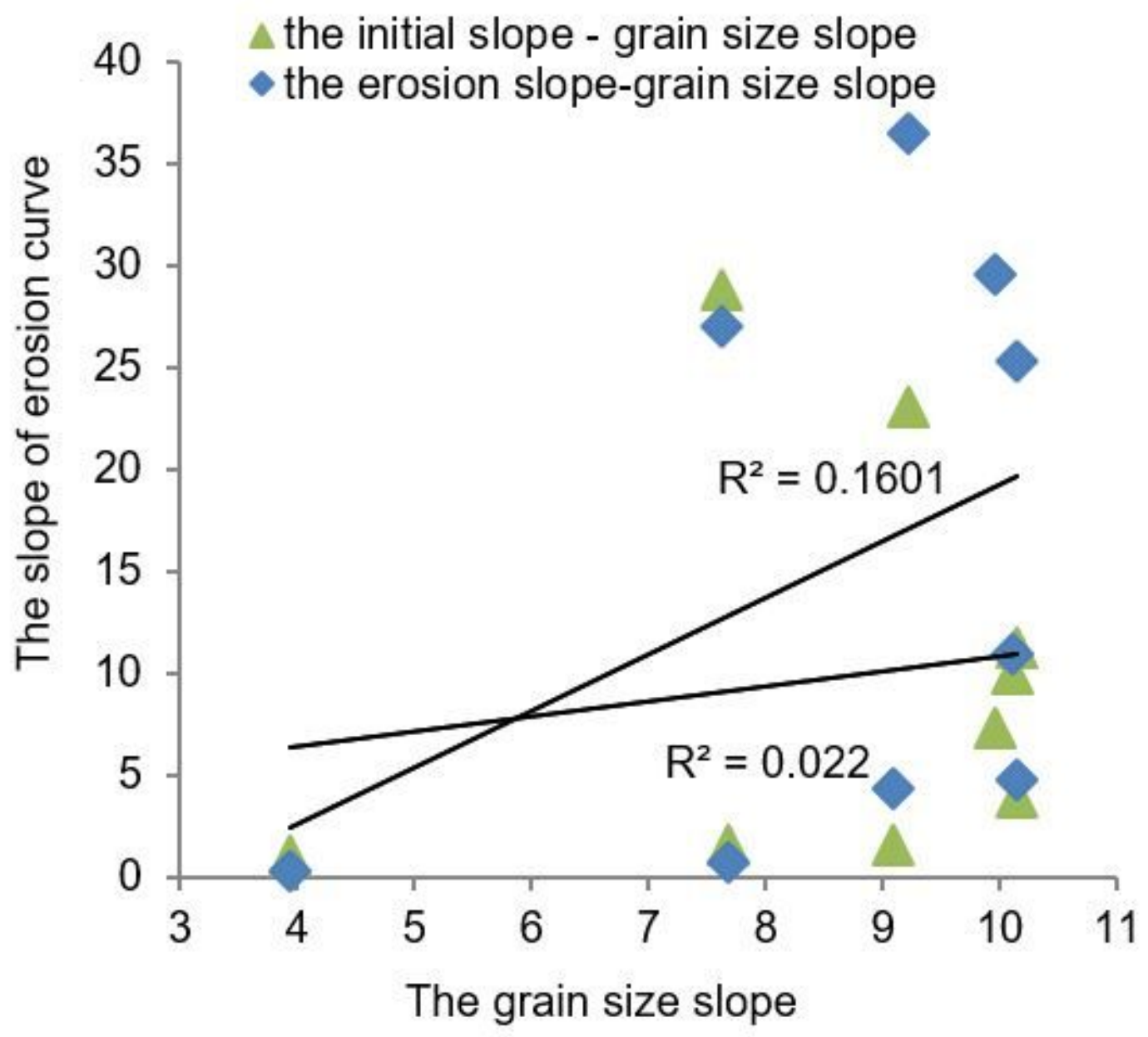

Figure 15

Erosion curve slope versus grain size slope 


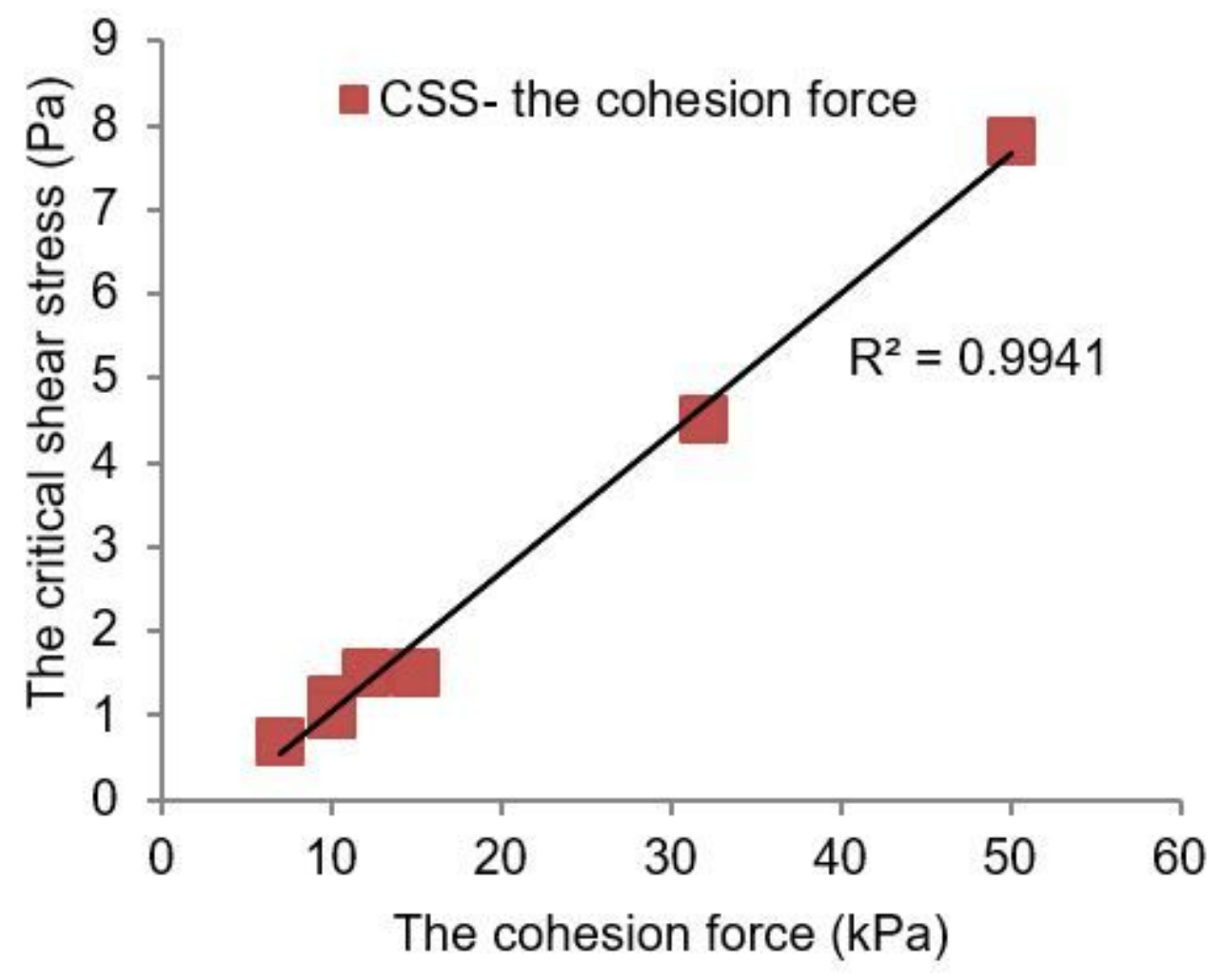

Figure 16

Critical shear stress (CSS) versus cohesion force 


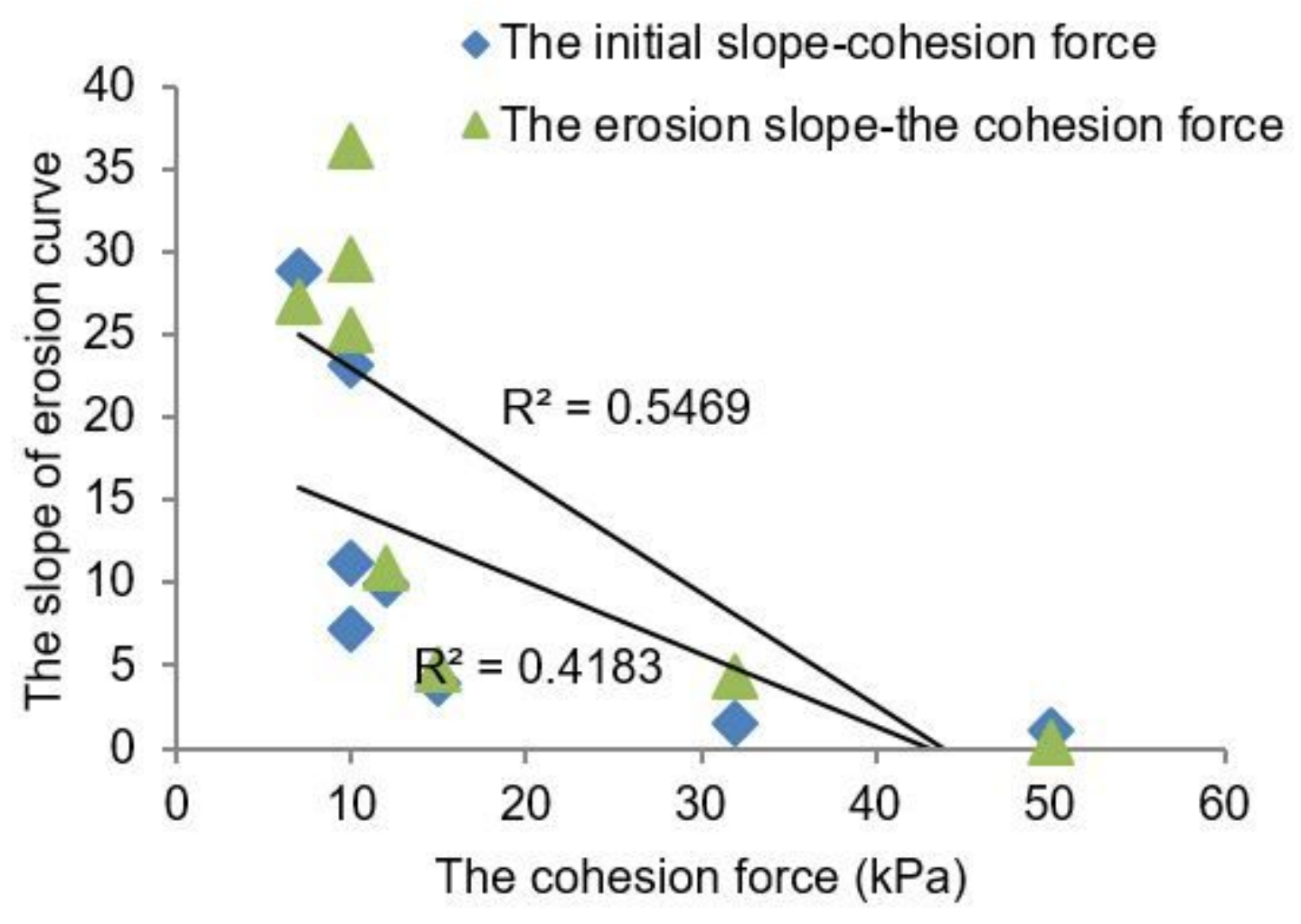

Figure 17

Erosion curver slope versus cohesion force 


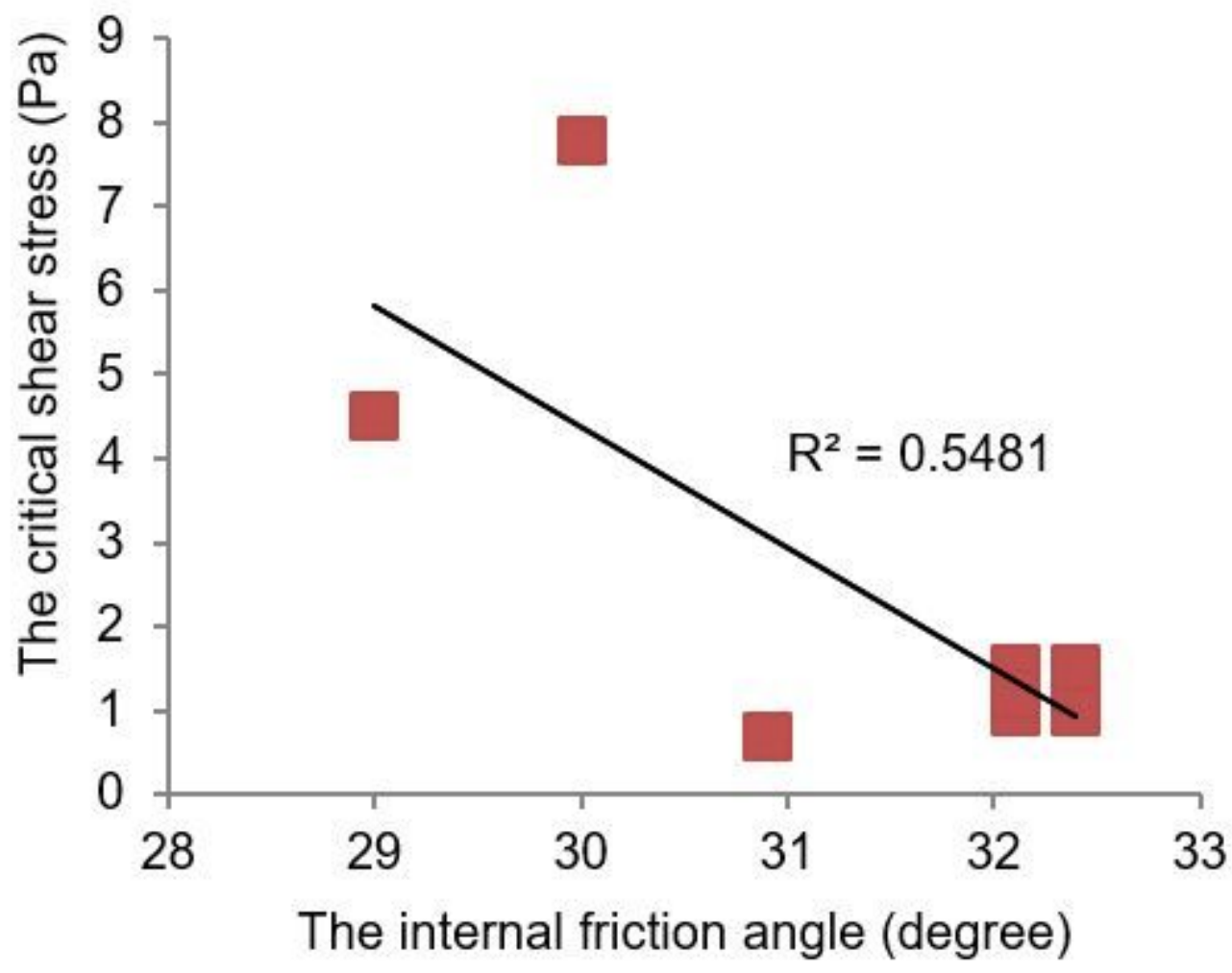

Figure 18

Critical shear stress versus internal friction angle 


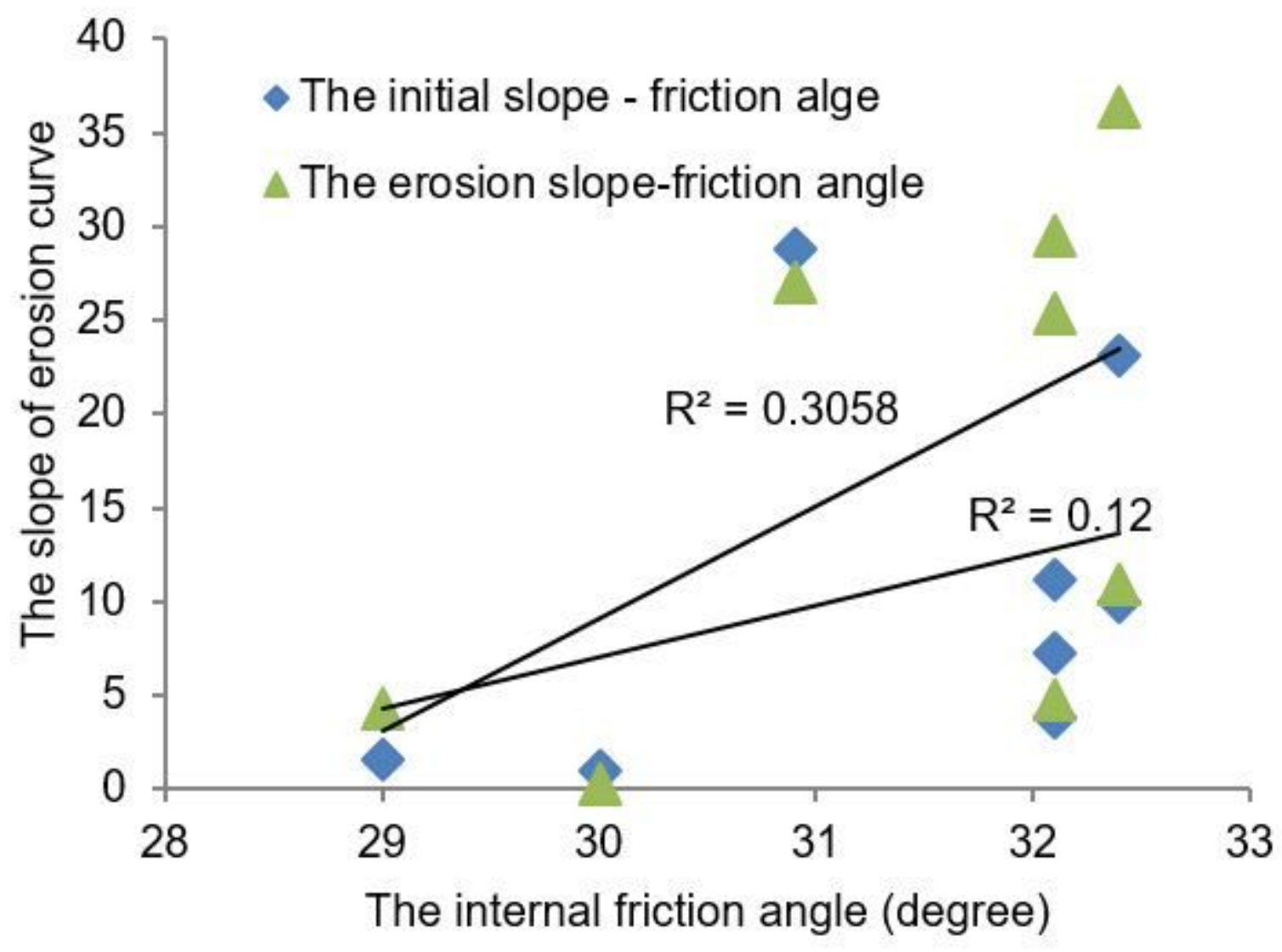

Figure 19

Erosion curve slope versus cohesion force 


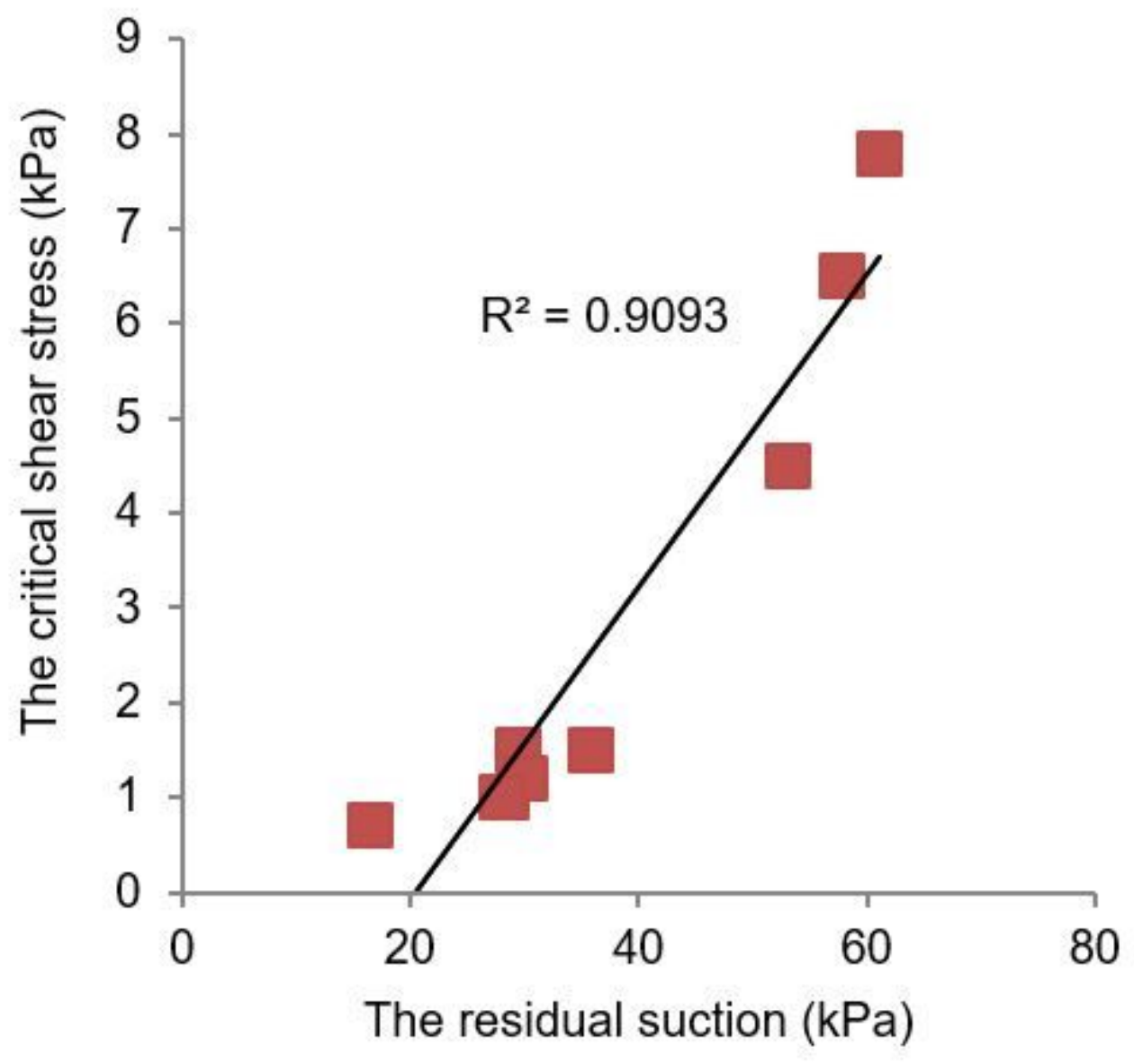

Figure 20

Critical shear stress versus residual suction 


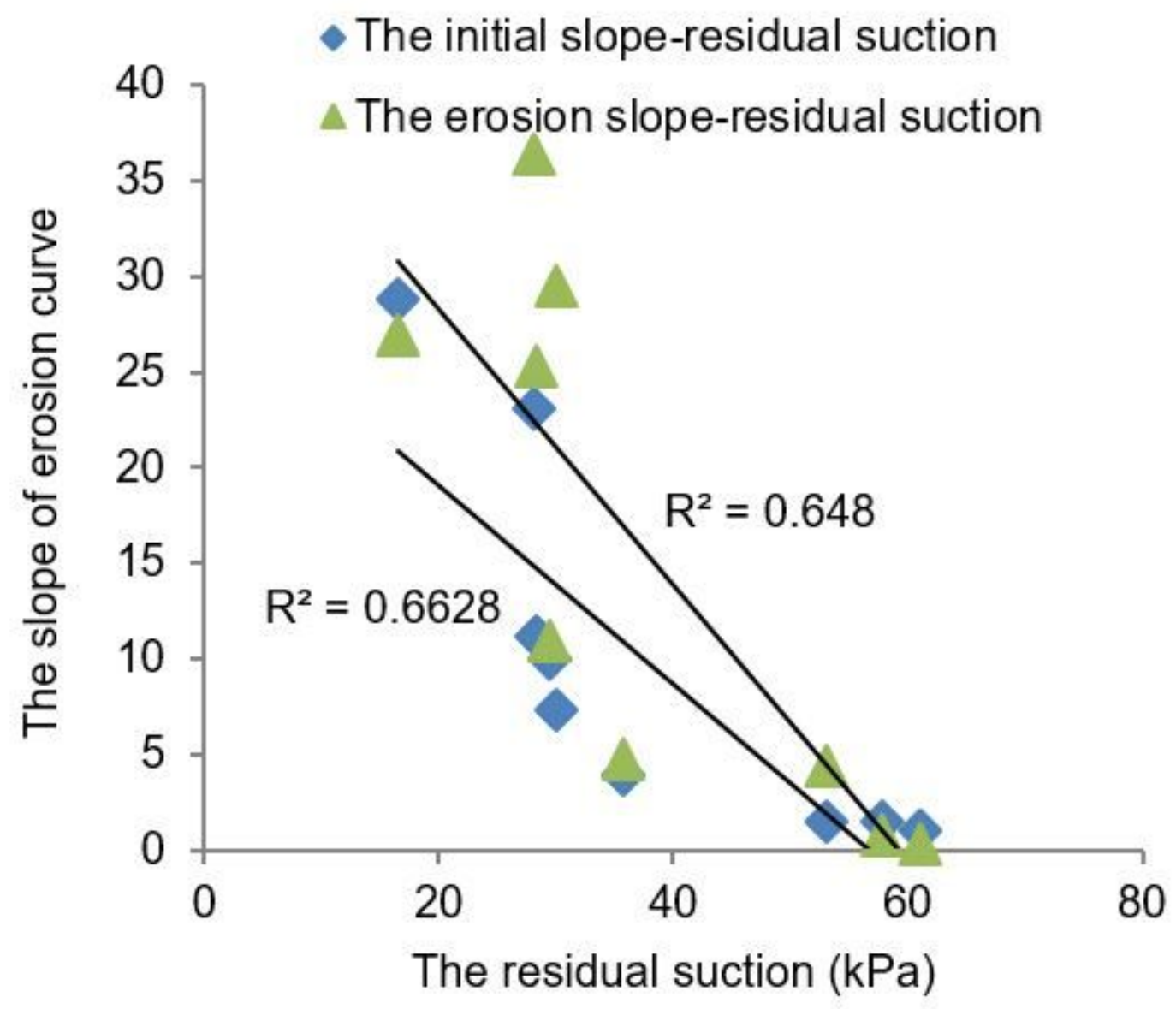

Figure 21

Erosion curve slope versus residual suction 


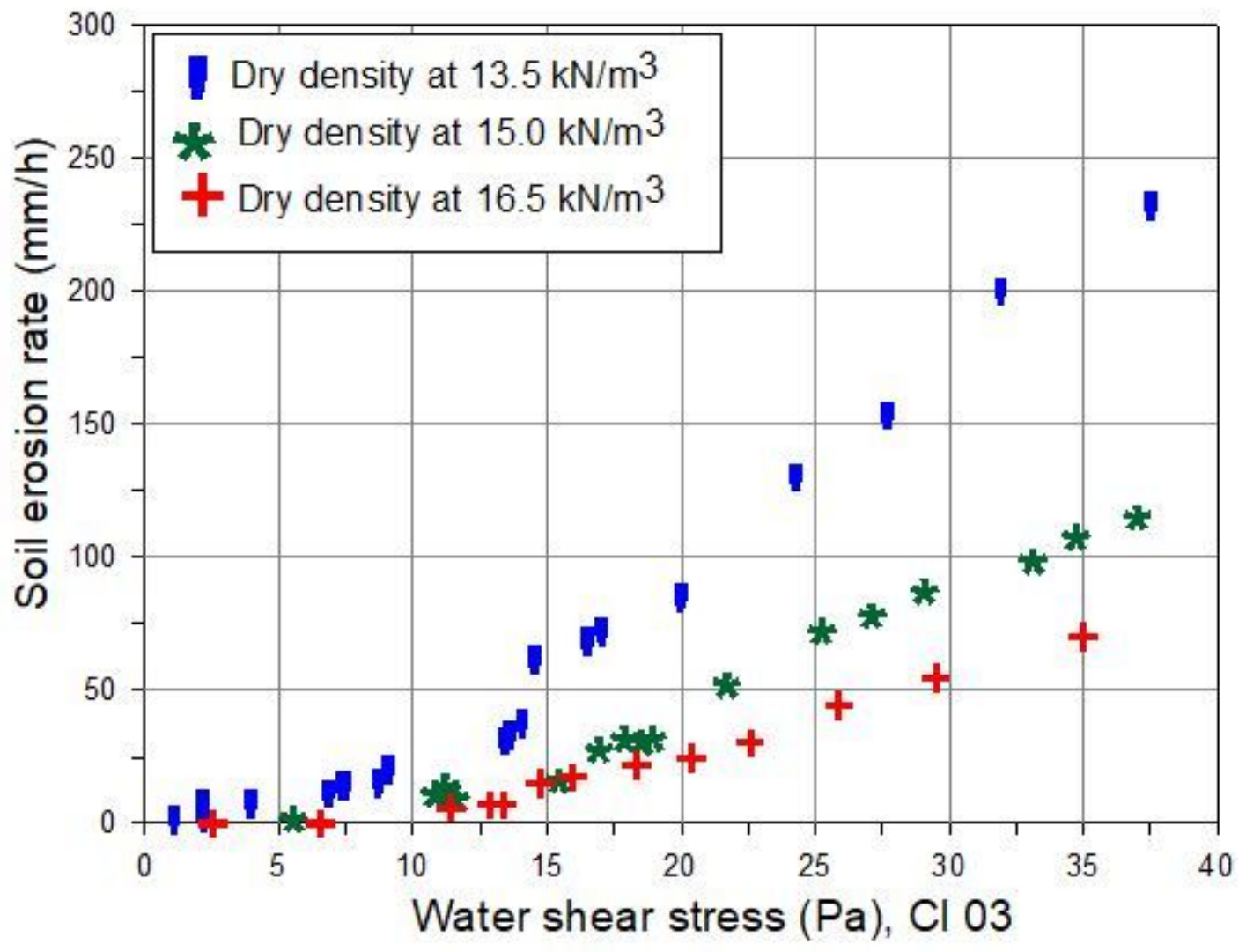

Figure 22

Erosion rate of $\mathrm{Cl} 03$ 


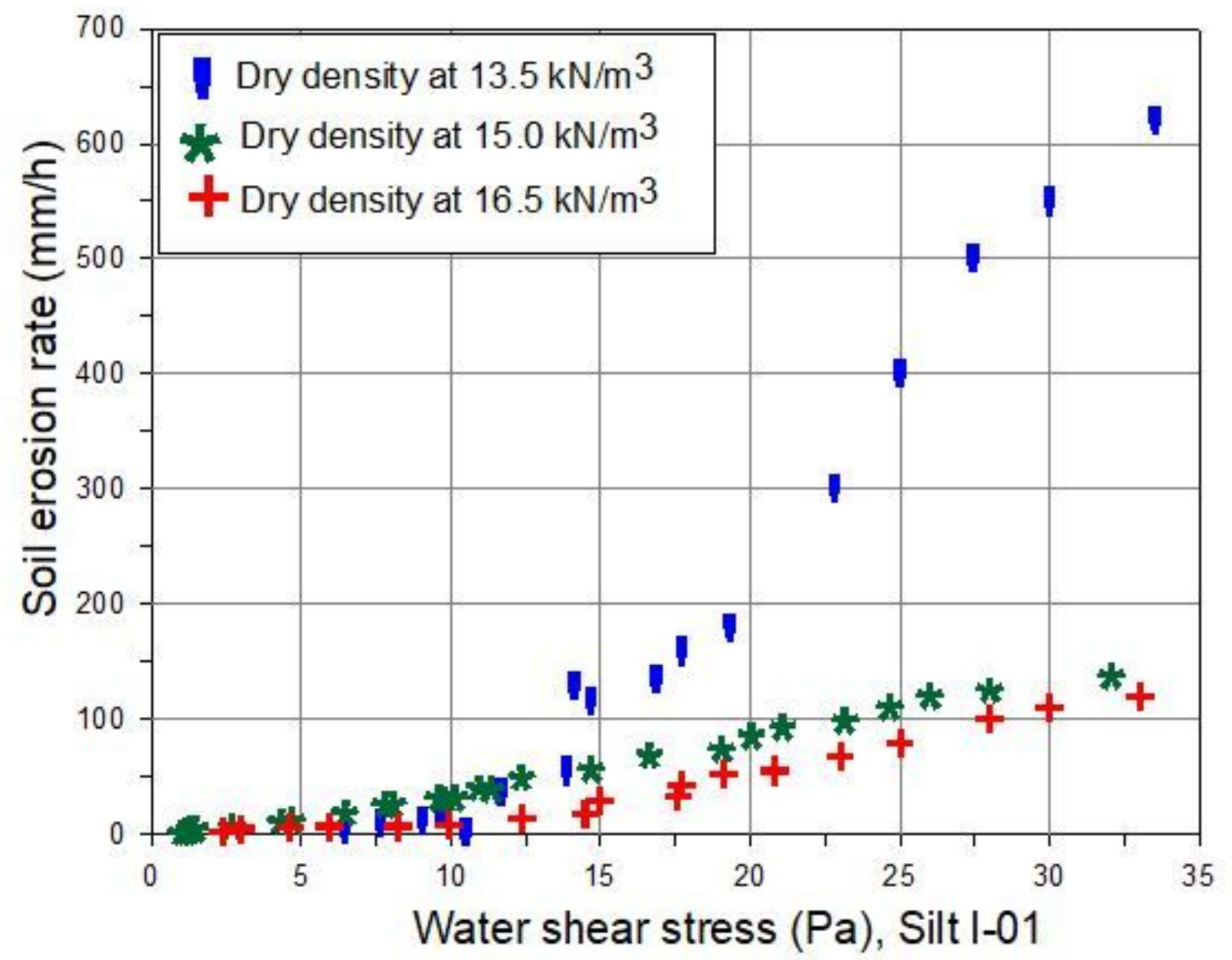

Figure 23

Erosion rate of Silt I-01 


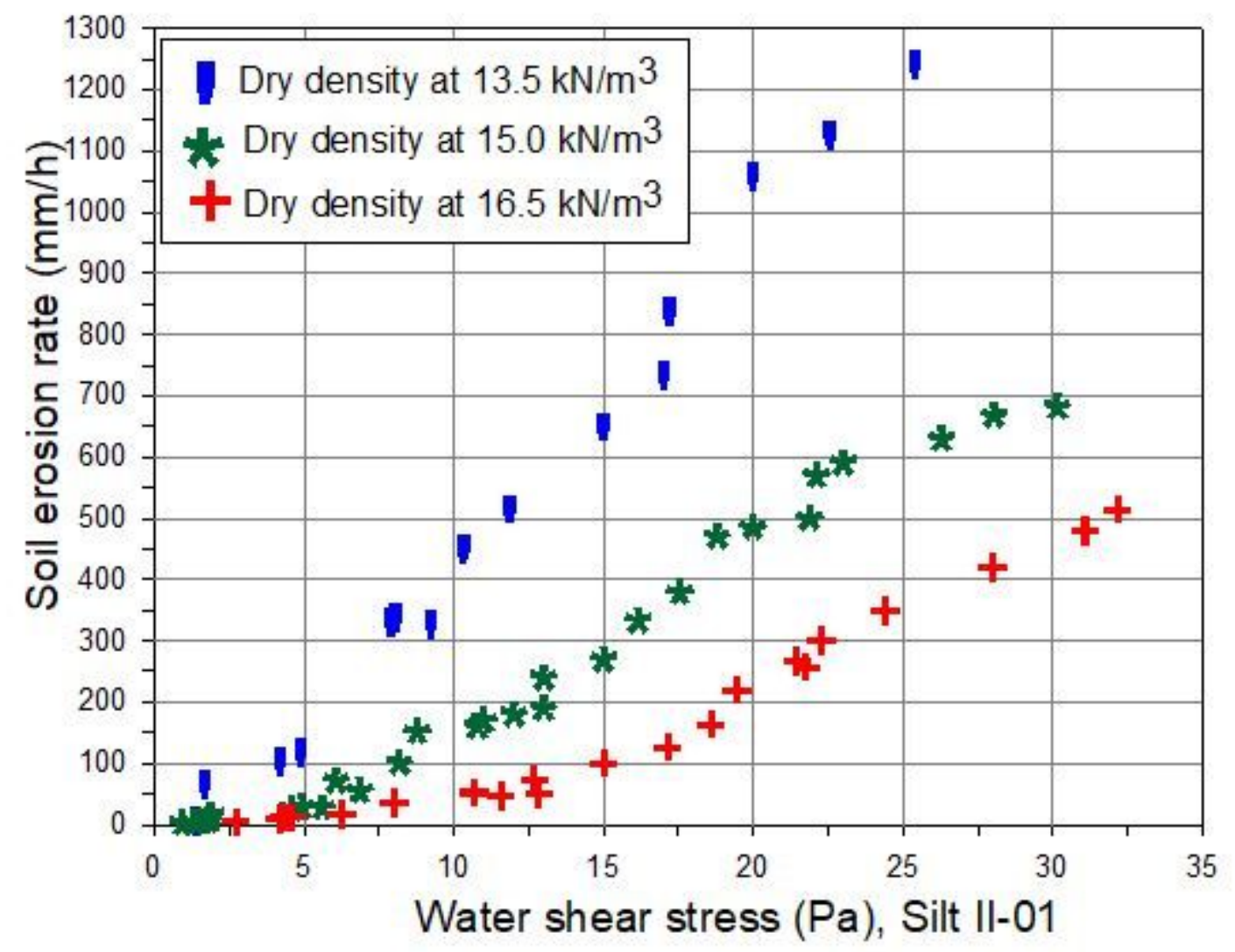

Figure 24

Erosion rate of Silt I-03 


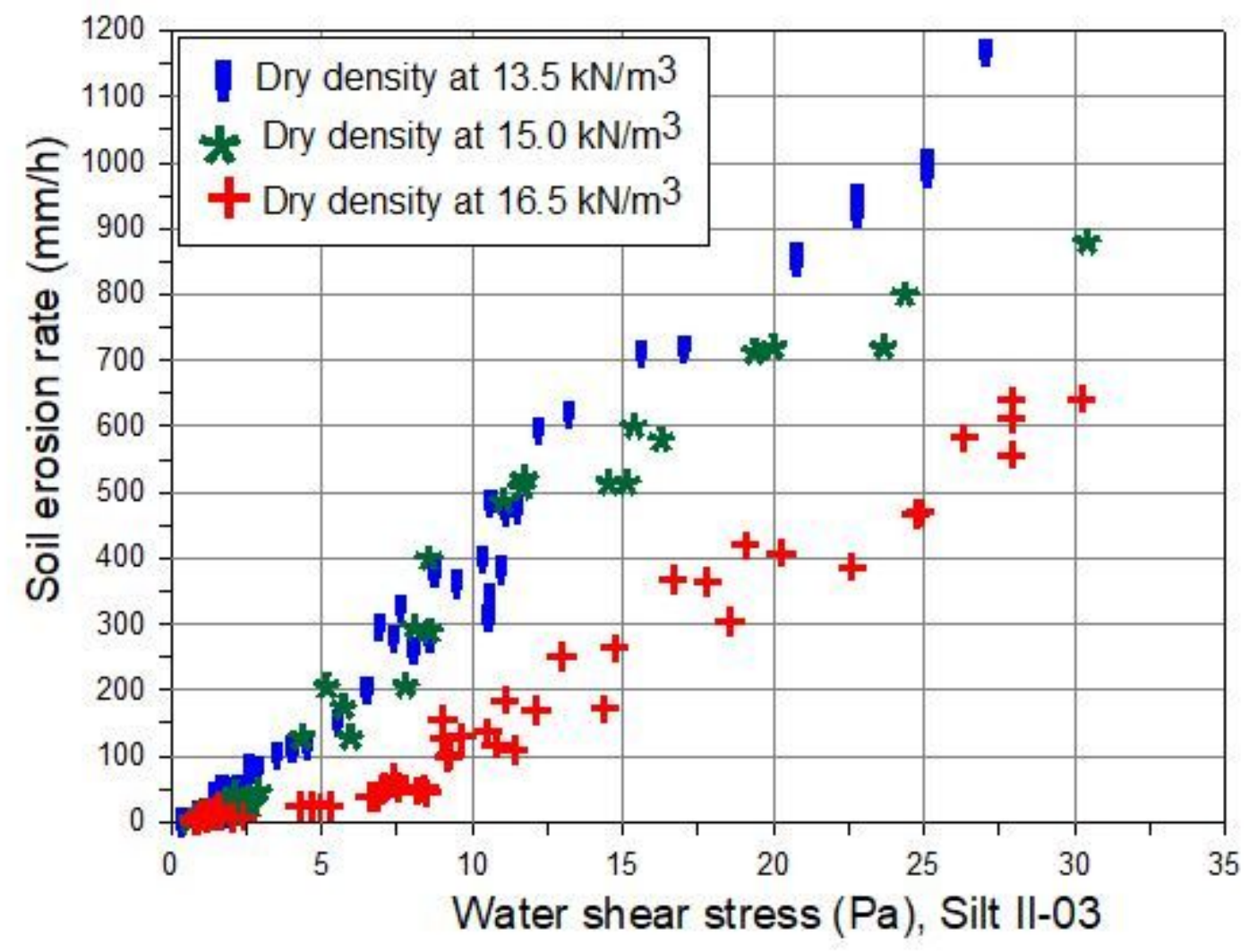

Figure 25

Erosion rate of Silt II-03 


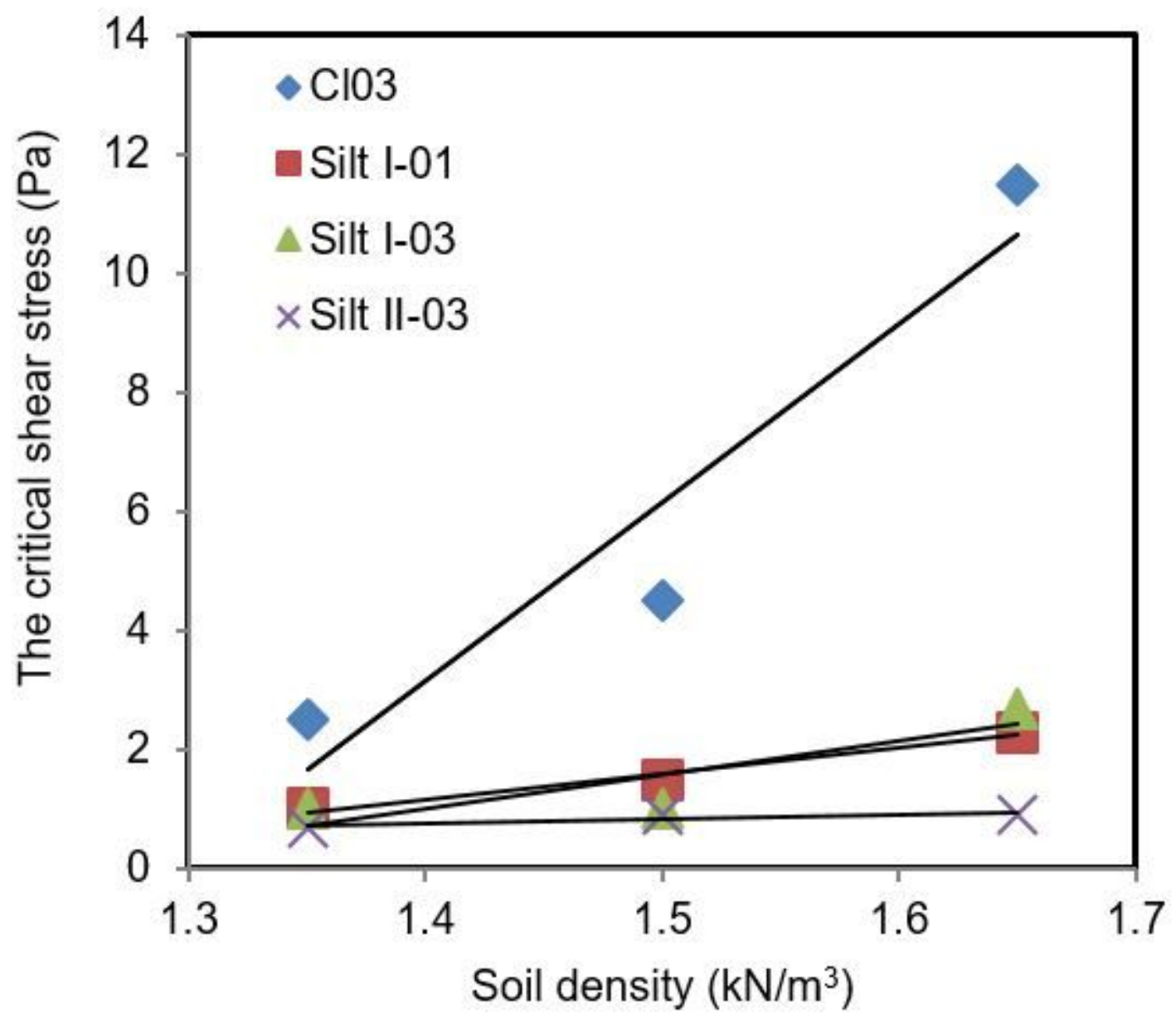

Figure 26

Critical shear stress at different dry densities 


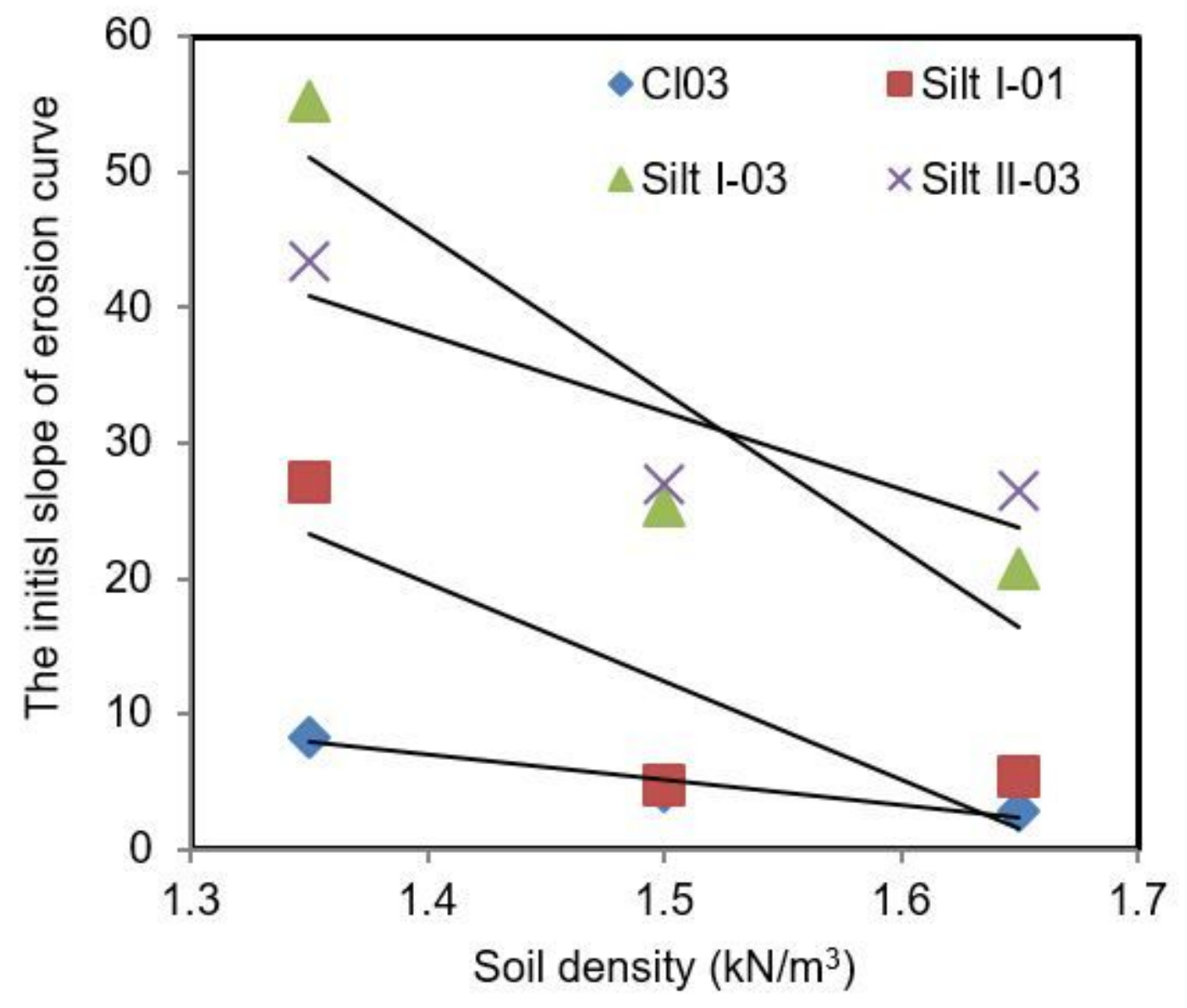

Figure 27

The initial slope of erosion curve at different dry densities 

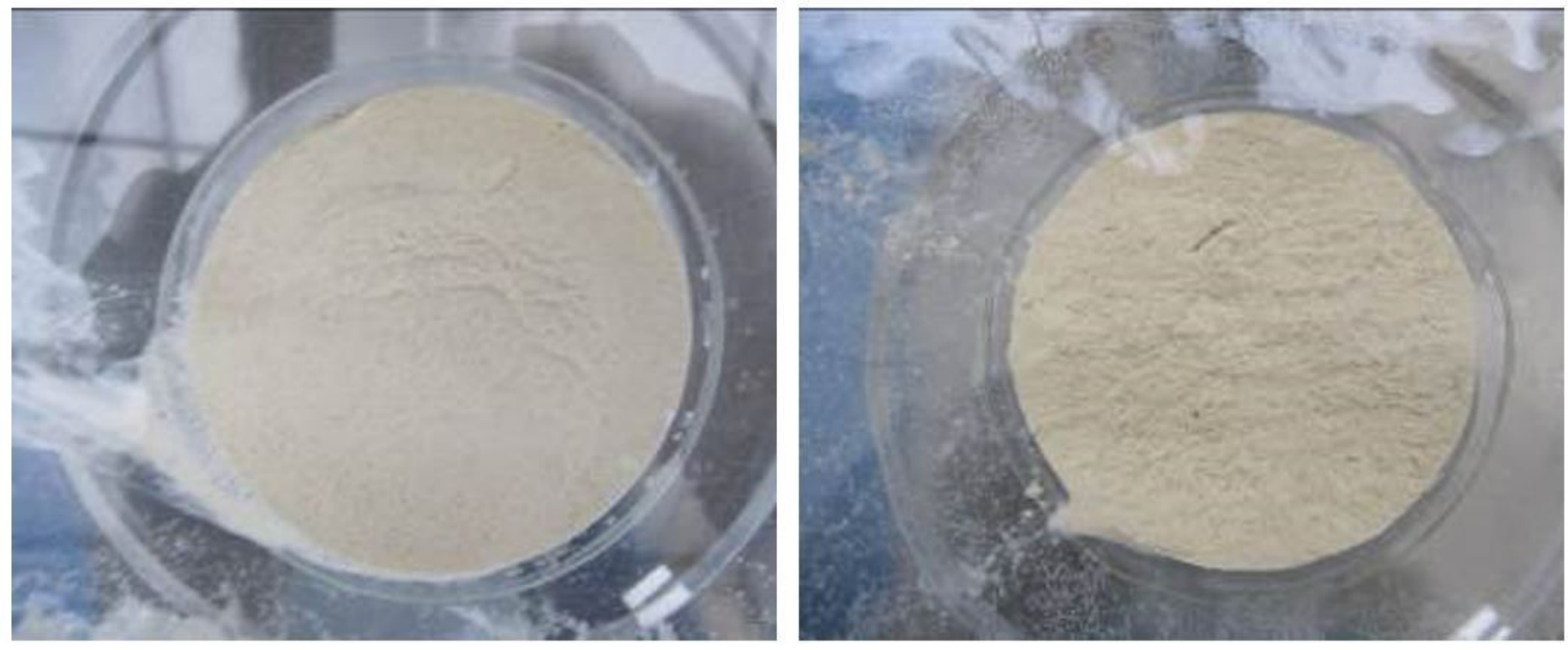

Figure 28

Surface erosion in silt soils (Silt II-03 at left, Silt I-03 at right)
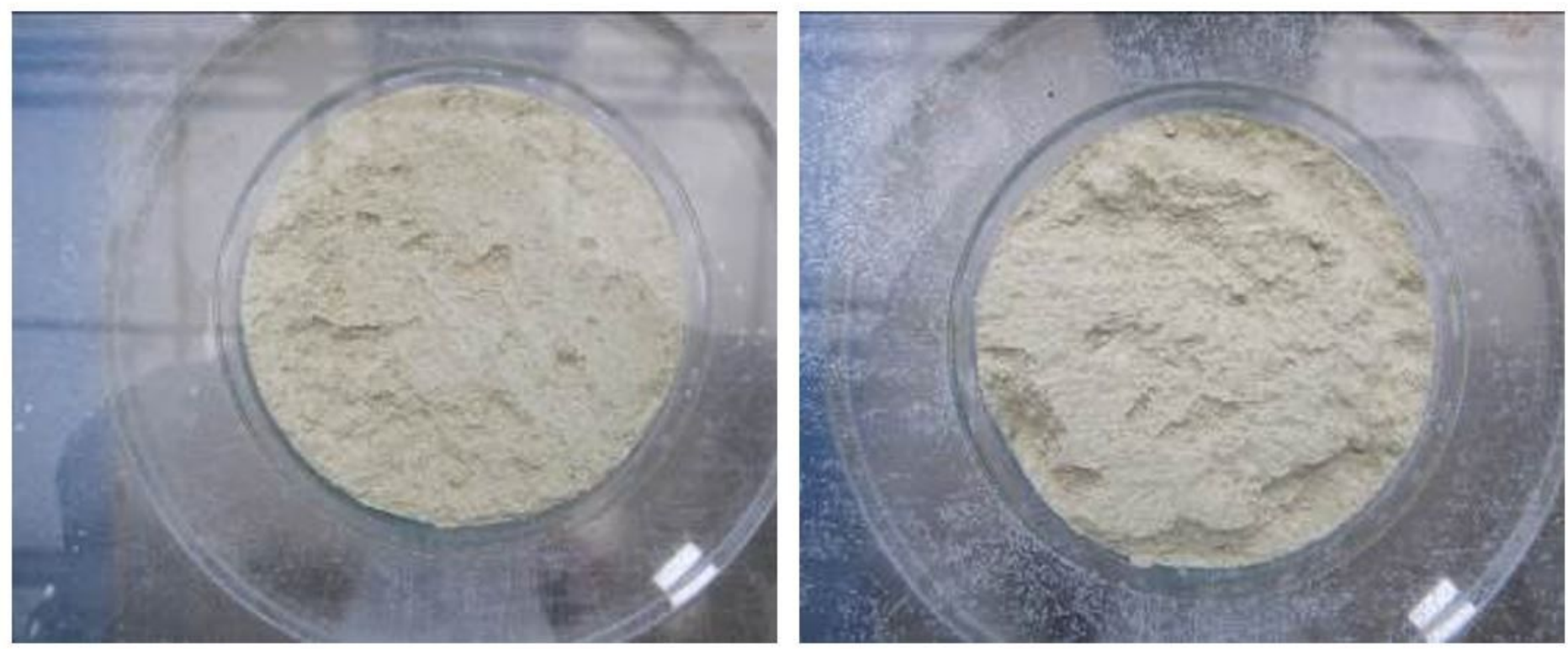

Figure 29

Surface erosion in Clay soil ( $\mathrm{Cl} 01$ after $5 \mathrm{~min}$ and $10 \mathrm{~min}$ at a water velocity of $0.5 \mathrm{~m} / \mathrm{s}$ ) 